\title{
AGGREGATE EMPLOYMENT \\ DYNAMICS: BUILDING FROM \\ MICROECONOMIC EVIDENCE
}

\author{
Ricardo J. Caballero \\ Eduardo M.R.A. Engel \\ John Haltiwanger
}

Working Paper No. 5042

\author{
NATIONAL BUREAU OF ECONOMIC RESEARCH \\ 1050 Massachusetts Avenue \\ Cambridge, MA 02138 \\ February 1995
}

We are grateful to Fischer Black, Olivier Blanchard, Axel Borsch-Supan, Peter Diamond, Francis Kramarz, James Stock, Randall Wright, seminar participants at Census, Chicago, Cornell, Harvard, Kentucky, Maryland, MIT, Pennsylvania, UQAM, the NBER Summer Institute 1993 (EFCC), the NBER Economic Fluctuations Meeting (July 1994), the C.V. Starr Center Conference on Productivity, Finance and Real Activity, the Labor Market Dynamics conference sponsored by the University of Paris I, and the ZEW conference on industry and employment dynamics for their comments. Laura Power provided outstanding research assistance. Ricardo Caballero acknowledges financial support from NSF and the Sloan Foundation. Eduardo Engel acknowledges financial support from FONDECYT (Chile) Grant 92-901. John Haltiwanger acknowledges financial support from the NSF and Census Fellow program. This paper is part of NBER's research programs in Economic Fluctuations and Labor Studies. Any opinions expressed are those of the authors and not those of the National Bureau of Economic Research.

(C) 1995 by Ricardo J. Caballero, Eduardo M.R.A. Engel and John Haltiwanger. All rights reserved. Short sections of text, not to exceed two paragraphs, may be quoted without explicit permission provided that full credit, including $\odot$ notice, is given to the source. 


\title{
AGGREGATE EMPLOYMENT \\ DYNAMICS: BUILDING FROM \\ MICROECONOMIC EVIDENCE
}

\begin{abstract}
This paper studies quarterly employment flows of approximately 10,000 large U.S. manufacturing establishments during 1972:1-1980:4. After estimating the extent of short run microeconomic substitution between employment and hours per worker (hours-week), we construct measures of the path of the deviation between actual and desired employment based on the observed behavior of establishments' hours-week. These deviations are then used as the state variables upon which units decide their employment adjustments (microeconomic policy). Using this framework we obtain the following conclusions: (i) Microeconomic employment adjustment policies are non-linear, with firms adjusting to large deviations proportionally more than to small ones. (ii) Employment adjustments are often either large or nil, suggesting the presence of non-convexities in the adjustment cost technologies. (iii) Between 60 and 90 percent of aggregate employment fluctuations is due to changes in the cross sectional distribution of employment deviations, while the remainder is due to changes in microeconomic policies. (iv) The bulk of net aggregate employment fluctuations due to changes in the cross sectional distribution is accounted for by aggregate shocks. This holds in spite of significant fluctuations in the distribution of idiosyncratic shocks and the marked countercyclical nature of their second moment (i.e. reallocation shocks). (v) Similarly, the bulk of net aggregate employment fluctuations due to changes in microeconomic policies is accounted for by aggregate shocks. (vi) Aggregate shocks are also the dominant source of job destruction, but account for less than half of the fluctuations in job creation. (vii) A simple parametric version of the aggregate model suggested by the microeconomic nonlinearities described above has a mean square error 50 percent lower than that of its linear counterpart.
\end{abstract}

Ricardo J. Caballero

Department of Economics

M.I.T.

Room E52-252g

Cambridge, MA 02139

and NBER
Eduardo M.R.A. Engel

PO Box 3445

Santiago

CHILE

and NBER
John Haltiwanger

Department of Economics

University of Maryland

College Park, MD 20742

and NBER 


\section{INTRODUCTION}

Since adjusting employment is costly, in most periods establishments choose employment levels different from what would be optimal in the absence of frictions. In the presence of adjustment costs, establishments' employment choices depend not only on current and expected future conditions, but also on past employment decisions. At each point in time, an establishment inherits the deviation between actual and "desired" employment levels left by its incomplete adjustment during previous periods. New aggregate and idiosyncratic shocks modify the deviation, and what is left of this deviation after the firm's adjustment during the current period is bequeathed to the next period. Following this chain of events methodically for a large number of establishments can shed substantial light on many important aspects of microeconomic and macroeconomic employment adjustment. This paper characterizes and organizes U.S. manufacturing plant level employment data accordingly. ${ }^{2}$

We start by relating the changes in a plant's deviation between actual and "desired" employment to the fluctuations in the plant's hours per worker. Conditional on these deviations and actual employment adjustments, aggregate and idiosyncratic shocks are recovered from simple "accounting" relationships. We then study the relation between the measures of employment deviations, the nature of shocks, and subsequent employment adjustments. We group our findings into three categories: (i) characterization of microeconomic adjustment policies, (ii) decomposition of sources of aggregate net employment fluctuations, and (iii) decomposition of sources of gross employment flows.

\section{Characterization of microeconomic adjustment policies:}

The deviation between actual and desired employment is undoubtedly one of the main state variables in any model of adjustment. We simplify our analysis substantially by making this deviation the only state variable, besides calendar time, upon which plants decide by how much to adjust their employment levels at each moment. We find that:

\footnotetext{
${ }^{2}$ There are several strands of literature related to this paper. On many aspects of the methodology and qualitative findingn, the paper in clonely linked to the literature on aggregate dynamica in the presence of fixed conts on microeconomic adjutment $((S, s)$ modelo). See, e.g., Blinder (1981), Caplin (1985), Caplin and Spulber (1987), Caballero and Engel (1991), Bertola and Caballero (1990), Bar-llan and Blinder (1992), Caplin and Leahy (1991), Caballero (1993), Hamermeat (1993), Caballero and Engel (1992,1993), Eberly (1994), and Beaulieu (1991). There is a clonely related licerature that (like this paper) exploits plant level data to investigate the importance of lumpy changes in plant level employment (see, e.g., Hamermesh (1989), Davis and Haltiwanger (1992), and Bresanhan and Ramey (1994)). On the relative contribution of aggregate and reallocation shocks to the business cycle, the antecedents of the paper include Lilien (1982), Abraham and Katz (1986), Blanchard and Diamond $(1989,1990)$ and Davis and Baltiwanger $(1990,1994)$. The paper is also obviously linked to the long literature on dynamic labor demand modela - see Hamermesh (1993) for a comprehensive discussion of the relevant literature.
} 
(i.1) Firms are more likely to react (or react by more) to large employment deviations than to small ones. For example, on average, about 70 percent of a 10 percent deviation will remain one quarter later; while only 50 percent of a 50 percent deviation will go beyond the current quarter. (i.2) Microeconomic employment adjustment is lumpy and discontinuous. Most distributions of adjustments (conditional on initial deviations) are bimodal: Invariably, one of the modes is at zero adjustment. Especially for large initial deviations, the other mode is typically at one (full adjustment). These features are akin to $(S, s)$ type models.

\section{Decomposition of sources of aggregate net employment fluctuations:}

At any point in time, the change in aggregate employment is the result of the sum of changes in employment across a large number of plants. In terms of our framework of analysis, these microeconomic changes and their connection with the aggregate can be described in two steps. The first one asks, conditional on microeconomic policy functions (which relate adjustments to deviations), what are the employment deviations of establishments just before adjustment? We summarize the answer to this question in a cross-sectional distribution of employment deviations. The second step notes that a change in aggregate employment is the result of the sum over the product of microeconomic policy functions and cross sectional distribution of deviations. Mechanically, fluctuations in aggregate employment over time are due to fluctuations in microeconomic policy functions and in the distribution of deviations. More interestingly, these fluctuations are in turn due to aggregate and reallocation shocks, filtered through our self-contained framework encompassing microeconomic policies and distributional dynamics. We find that:

(ii.1) Between 60 and 90 percent of U.S. aggregate manufacturing employment fluctuations during the 1972:1-1980:4 period (our sample) is due to fluctuations in the cross-sectional distribution of employment deviations. (ii.2) Fluctuations in the cross-sectional distribution accounting for the changes in aggregate employment are almost entirely driven by aggregate shocks rather than by changes in the distribution of idiosyncratic shocks (reallocation shocks). This conclusion is reached despite the marked countercyclical nature of the second moment of the distribution of idiosyncratic shocks. (ii.3) Similarly, more than 90 percent of the fluctuations in microeconomic policies accounting for changes in aggregate employment are driven by aggregate rather than reallocation shocks. Putting all things together (shocks to distributions and to microeconomic policies), we conclude that (ii.4) aggregate shocks account for more than 90 percent of net employment fluctuations. (ii.5) The departure of the (nonlinear) microeconomic policies characterized in (i) from 
the standard linear model (partial adjustment or quadratic adjustment cost model), plays an important role in these decompositions. A simple parametric version of the aggregate model suggested by the microeconomic nonlinearities described above has a Mean Square Error 50 percent lower than that of its linear counterpart.

Decomposition of sounces of gross employment flows fluctuations:

Microeconomic employment adjustments can be grouped in many different ways. Of particular relevance is the construction of the gross flows leading to aggregate net employment changes. Adding over all those establishments that increase their employment levels at any point in time yields aggregate job creation during that period. Adding over those that reduce their employment levels, yields aggregate job destruction. Fluctuations in these (gross) flows can be characterized in terms similar to those used above for net employment changes. Doing so we find that:

(iii.1) About and at least half of fluctuations in job creation and destruction, respectively, are due to changes in the cross-sectional distribution of employment deviations. (iii.2) The bulk of fluctuations in gross flows is driven by aggregate shocks. (iii.3) Reallocation shocks explain (substantially) more than half of fluctuations in microeconomic policies leading to fluctuations in job creation while they explain (substantially) less than half of fluctuations in job destruction. Putting all things together (shocks to distributions and to microeconomic policies), we conclude that: (iii.5) Aggregate shocks account for about 40 percent of fluctuations in job creation and 90 percent of fluctuations in job destruction.

This introduction is followed by section 2, where we describe the basic framework and construct and estimate the mapping from hours-week to establishments' employment deviations. Section 3 characterizes microeconomic policies. Sections 4 and 5 decompose the sources of fluctuations in net and gross employment flows. Section 6 concludes.

\section{THE BASIC FRAMEWORK}

In this section we describe the basic framework we use to structure our discussion of the relation between the microeconomic features of the data and aggregate dynamics. In doing so, we distinguish between identities that follow from the definitions we introduce and theory-dependent statements. We present the issues in reverse order. In the first two subsections we describe the relationship between microeconomic employment deviations (i.e. the difference between actual and desired-frictionless employment) and aggregate employment dynamics, for given deviations. In the third subsection we describe the theory 
and measurement of these deviations.

\section{1 "Accounting"}

We start by defining $z$ as a single index measuring the deviation between actual and desired (log of) employment, $e$ and $e^{*}$ :

$$
z_{i t} \equiv e_{i, t-1}-e_{i t}^{*},
$$

where the subindices $i$ and $t$ denote firm $i$ and time $t$, respectively. Based on this measure of employment deviation we build our "accounting" framework; the quotation marks reflect the fact that $z$ depends on $e^{*}$, which is a theoretical construct.

We define $A(z, t)$ as the fraction of the employment deviation by which a firm with deviation $z$ during time period $t$ adjusts on average, and label it the "effective hazard" function. This function can also be defined implicitly by noticing that the average (log of, hereon) employment change by firms that are at $z$ before adjusting is equal to $-z A(z, t)$.

It is important to realize that the definition of $A(z, t)$ is silent with respect to the way in which the average adjustment of firms at $z$ takes place. For example, this could be due to all firms adjusting by a small fraction (as in convex adjustment costs models) or by a few firms adjusting fully and most firms remaining inactive (as in non-convex adjustment costs models). The distinction between these different forms of adjustment policies will be discussed later in the paper.

The cross-sectional density of plants' deviations at time $t$, evaluated at $z$, is denoted by $f(z, t)$, so that the fraction of firms with deviations between $z$ and $z+d z$ at time $t$ is (approximately) equal to $f(z, t) d z$.

The definitions of the effective hazard and cross-sectional density of employment deviations permit us to define the variable $\Delta E_{t}$ as:

$$
\Delta E_{t} \equiv-\int z A(z, t) f(z, t) d z
$$

If employment shares are independent of the position of firms in the space of employment deviations - so that the average of firms' employment growth rates is equal to the growth rate of the aggregate - then $\Delta E_{t}$ is equal to the rate of growth of aggregate employment: $E_{t}-E_{t-1}$. We make this independence assumption and refer to $\Delta E_{t}$ as the aggregate change in employment (all variables are in logarithms). ${ }^{3}$

\footnotetext{
${ }^{3}$ This assumption is validated by the data: for our sample, aggregate quarterly employment growth has
} 


\subsection{Cross-sectional and aggregate fluctuations}

From equation (2) we see that fluctuations in aggregate employment growth can be explained in terms of fluctuations in the effective hazard and in the cross-sectional density of employment deviations. We will attempt to separate these two "sources" of fluctuations in the empirical section. Yet it is important to emphasize at the outset that even if the effective hazard remains unchanged, its shape plays a key role when mapping changes in the cross-sectional density of deviations into aggregate employment, as well as when tracking the evolution of this density. We briefly illustrate the latter below and then study in more detail the mechanisms behind fluctuations in the cross-section of deviations.

\subsubsection{On the shape of the effective hazard function}

A basic conclusion emerging from the literature on aggregation of $(S, s)$-type models is that the first moment of $f(z, t)$ is not enough to capture the impact of cross-sectional dynamics on aggregate employment, as would be the case with standard linear models (e.g., quadratic-adjustment-costs model). More generally, it follows from equation (2) that as long as the effective hazard function depends on $z$, aspects of $f(z, t)$ other than its mean influence aggregate dynamics.

For example, if the fraction of the deviation between actual and desired employment that is closed on average grows with the extent of the employment deviation according to $A(z)=\lambda_{0}+\lambda_{2} z^{2}$, with $\lambda_{0}>0$ and $\lambda_{2}>0$, then equation (2) implies that:

$$
\Delta E_{t}=-\lambda_{0} M_{z}^{(1)}(t)-\lambda_{2} M_{z}^{(3)}(t)
$$

where $M_{z}^{(i)}(t)$ denotes the $i^{\text {th }}$ (non-central) moment of the cross-sectional distribution of deviations at time $t$. Or in terms of central moments (but for the first one),

$$
\Delta E_{t}=-\lambda_{0} \mu_{z}(t)-3 \lambda_{2} \mu_{z}(t) \sigma_{z}^{2}(t)-\lambda_{2} \mu_{z}^{3}(t)-\lambda_{2} \sigma_{z}^{3}(t) \gamma_{z}(t)
$$

where $\mu_{2}(t), \sigma_{z}(t)$ and $\gamma_{2}(t)$ denote the mean, standard deviation and skewness coefficients of the cross-sectional distribution of deviations at time $t$. In this simple example, higher moments of the cross-sectional density of deviations affect the evolution of aggregate employment through mean-variance and variance-skewness interaction terms. We also have that the first moment affects aggregate dynamics in a non-linear fashion.

a mean of 0.001 and a standard deviation of 0.023 . Our $\Delta E_{t}$ seriea computed from (2) has a mean of 0.002 and a standard deviation of 0.023 . Moreover, the correlation between the two series is 0.96 . 
One of the main goals of this paper is to characterize the function $A(z, t)$ empirically. As emphasized above, doing so will not only shed light on the nature of microeconomic adjustment, but it will also add a key piece of information for understanding aggregate employment dynamics.

\subsubsection{On the dynamics of the cross-section of employment deviations}

The change in a firm's deviation during period $t, \Delta z_{i t}$, can be decomposed into the sum of three components:

$$
\Delta z_{i t}=\Delta e_{i t-1}-\Delta E_{t}^{*}-v_{i t},
$$

where $\Delta x_{t}=x_{t}-x_{t-1}$, and the last two terms represent a decomposition of the change in desired employment, $\Delta e_{i t}^{*}$, into an economy-wide average change in desired employment, $\Delta E_{t}^{*}$, and a plant-specific (idiosyncratic) shock, $v_{i t}$ (which by definition has zero mean when averaged across plants for a specific time-period), so that:

$$
\Delta e_{i t}^{*}=\Delta E_{t}^{*}+v_{i t}
$$

Since we are working in discrete time, it is important to make explicit the timing convention for shocks and adjustments. We assume that each period starts with firms' idiosyncratic shocks, continues with the agregate shock, and ends with firms' adjustments. Associated to each of these events there is a cross-sectional density of deviations. The density at the end of the previous period - that is, before any shock takes place at time $t$ - is denoted by $f_{1}(z, t-1)$; firms' corresponding deviations are denoted by $z_{i, t-1}^{1}$. The density that results after the idiosyncratic shock, $v_{i t}$, is denoted by $f_{2}(z, t)$. Next comes the aggregate shock, $E_{t}^{*}$, which leads to deviations denoted by $z_{i t}$ and density $f(z, t)$. At the end of period $t$ firms adjust employment (by $\Delta e_{i t}$ ) and hours (by $\Delta h_{i t}$ ). The resulting density is $f_{1}(z, t)$, and the cycle begins again.

More explicitly, the evolution of the density of deviations during period $t$ is affected by three inputs: First, the initial density (final density of previous period) $f_{1}(z, t-1)$ is convolved with the density of idiosyncratic shocks. To accommodate our empirical findings, we let the latter depend on initial deviations and denote it by $g(v, t \mid z){ }^{4}$ Thus:

$$
f_{2}(z, t)=\int f_{1}(z-v, t-1) g(v, t \mid z-v) d v .
$$

\footnotetext{
'One source of correlation, perhaps the main one, between deviations and idiosyncratic shocks is (negative) serial correlation in the latter, mostly arising from transitory components due to seasonal factors.
} 
Second, there is an aggregate shock that shifts all units by $-\Delta E_{t}^{*}$ in state-space, yielding $f(z, t)$. Finally, denoting by $Z_{t}$ and $Z_{1, t}$ the random variables corresponding to $f(z, t)$ and $f_{1}(z, t)$, we have that $Z_{1, t}=Z_{t}\left(1-J_{t}\right)$, where $J_{t}$ denotes the fraction of its deviation by which a firm adjusts. We denote the density of the latter by $a(j, t \mid z)$, which satisfies the constraint $A(z, t)=\int j a(j, t \mid z) d j$, and write down for later use the expression summarizing this last step:

$$
f_{1}(z, t)=\int \frac{1}{u} a\left(1-u, t \mid \frac{z}{u}\right) f\left(\frac{z}{u}, t\right) d u .
$$

\subsection{Measuring microeconomic deviations}

The previous section is accounting, given a measure of $z$. In order to construct an estimate of $z$ we assume that the technology and wage schedules are such that if firms did not face costs of adjusting their level of employment, they would always keep the same number of hours per worker. On the other hand, if costs of adjusting employment are larger - at least in the short run - than those of changing the number of hours per worker, then hours per worker will be positively correlated with the degree of firms' deviations. ${ }^{5}$ Caballero and Engel (1993) present a formal link, based on Bils (1987), between our $z^{1}$ and measures of hours per worker. We borrow from them the expression: 6

$$
\Delta z_{i, t}^{1}=-\theta_{i t} \Delta h_{i t}
$$

which says that as the (log of) hours per worker in firm $i$ at time $t\left(h_{i t}\right)$ rises, the firm's labor-shortage increases.

Given the paths of $\left\{\Delta h_{i t}\right\}$ and the parameter $\theta_{i t}$, as well as an initial value $z_{i 0}^{1}$, we can use equation (8) to trace the path of $z_{i t}$. Repeating these steps for all firms allows us to provide empirical content to the decomposition of employment adjustment presented in the previous sections.

5 "When Cooper [Industried] had a sunge in onders for the computer cables it makes, more than 2,000 workers were acked to wort an additional two hours a day, on overtime pay. Only as a last resort has Cooper recently begun to hire. [...] People got tired of working 10hours days [...]," New York Times, Sunday May 16, 1993.

'In their model firmo' production functions are Cobb-Dongla in hours per worker and employment. Productivity and demand shock follow independent random walls. Firms are competitive in the labor market but face a (per hour) wage curve that is a function of the average number of hours worked. Adjuating average hours is costleas (see Sargeat (1978) and Shapiro (1986)), yet adjunting employment is not. It follow from these assumptions that a frm always chooses average houn to maximise its current profits, conditional on its current employment level. Comparing the actual employment level with that which would be optimal if employment could be adjusted costleady leads to the following expreacion, where depends on the demand-elasticity, the elasticity of the output with respect to both inputs and the wage equation. 
We estimate the values of the $\theta_{i t}$ 's under a variety of assumptions about similarities and differences across firms, sectors, seasons and time. Allowing for two-digit variation achieves a reasonable compromise between precision and flexibility; we describe these results below. ${ }^{7}$ The availability of plant level quarterly data for hours per worker limits our sample to 1972:1-1980:4 (see the Appendix A for further details).

Combining the definition of deviations in equation (1) with equation (8), yields:

$$
\Delta e_{i t}=-\theta_{i t} \Delta h_{i t}+\Delta e_{i t}^{*}
$$

In principle, the only unobservable in this equation is the (exogenous) shock $\Delta e_{i t}^{*}$. In practice, both employment and hours changes are likely to be measured with error - both because of data-problems as well as theory-problems (e.g. omitted state variables, transitory versus permanent shocks, etc.). Considering these factors, we rewrite the previous equation in a standard regression format:

$$
\Delta e_{i t}=\text { const }_{i}+\theta_{i t}\left(-\Delta h_{i t}\right)+\epsilon_{i t},
$$

where $\epsilon$ is an error term corresponding to the exogenous shock $\Delta e_{i t}^{*}$ and measurement error terms, after removing two-digit effects. Estimating $\theta$ from this equation is likely to yield downward biased estimates. There are two reasons for this: First, since hours are used to accommodate part of frictionless shocks $\left(\Delta e^{*}\right)$ when employment does not adjust fully, changes in hours and the component of $\epsilon$ due to the frictionless shock are positively correlated. Second, the measurement error in hours and changes in hours are also positively correlated.

A partial solution to the first problem, which is due to adjustment costs, emerges from the model itself. If firms' employment adjustments are infrequent and large, then we can use the observations of periods where an adjustment occurs, for in those episodes changes in employment and hours should be one order of magnitude larger than $\epsilon .^{8}$ If there was no measurement error in hours, this could be implemented by isolating the observations with relatively large changes in hours. Measurement error makes this difficult since the sorting

\footnotetext{
The overall reaulte of the paper are robust to several modifications. In particular, to allowing for time and/or seasonal effects.

'This is stricty true in continuons time if shocks have continuous sample paths. Here we are taking a stand on the nature of adjustment costa: non-convex. This will be validated later by onr finding on the distribations of conditional adjustments (whose validity does not depend on our particular estimates of $\theta$ ). Also, even if adjustment costs are convex, but leading to an increasing effective harard (which we will find), using observations with large changes reduces the bias induced by adjuatment costa.
} 
device is correlated with the residual of the equation. Another imperfect sorting device is to use observations with relatively large employment changes. This suffers from the same problem of hours since employment is also likely to be measured with error. However, if the measurement errors in employment and hours are not too correlated, it is possible to reduce the selection bias substantially by using the intersection of both selection criteria; that is, observations with large (in absolute value) changes in hours and employment. This is what we do. We estimate the equation above using only observations with changes that are larger than one standard deviation of the changes in employment and hours in each of our groups (see below).

Solving the first problem does not remove the measurement error bias, however. In order to reduce this problem we run a reverse regression (i.e., with $\Delta h$ on the left hand side) using the same observations. Due to the measurement error in employment, this yields an upward biased estimate of $\theta$. It follows that there is a convex combination of the downward biased estimate of $\theta, \hat{\theta}_{1}$, and the upward biased one, $\hat{\theta}_{2}$, that minimizes the mean squared error. Calling this estimator $\hat{\theta}$, we have:

$$
\hat{\theta}=\alpha \hat{\theta}_{1}+(1-\alpha) \hat{\theta}_{2},
$$

where $\alpha$ is chosen to minimize the mean squared error, under the assumption that measurement error in employment and hours are uncorrelated and have equal variance, and these in turn are equal to the variance of the signals. This configuration of parameters yields a value of $\alpha$ of 0.67 for large samples (more than 200 observations) and a value of $\alpha$ that approaches 1 as the sample size becomes sufficiently small (less than 40 ). Given the specification emphasized in the main text of the paper with 20 estimated $\theta$ s (i.e., by 2-digit industry), the typical industry has a large number of observations so that the mean $\alpha$ across industries equals 0.69 .

The magnitude of the 20 estimated $\theta$ s (and the underlying $\theta_{1} \mathrm{~s}$ and $\theta_{2} \mathrm{~s}$ ) are depicted in Figure 2.1. The estimated $\theta$ are fairly constant across sectors. The mean $\theta$ is 1.20 ; it varies from 0.93 in Apparel to 1.36 in Petroleum. ${ }^{9}$ The sign of $\theta$ is systematically positive, as postulated above. That is, firms substitute hours per worker for employment: adjustments in employment bring about adjustments of opposite sign in hours per worker (remember that the regressor is $-\Delta h$ rather than $\Delta h$ ). This negative correlation is a robust and interesting

\footnotetext{
'These estimates are small when compared with those calibrated by Caballero and Engel (1993), using the eatimates for the marginal cont of an additional hour-week in Bils (1987). One posaible explanation for this difference is that here we are using establishmeat level data, where hours are subatantially more volatile (relative to employment) than at the two-digit level, which is the level of aggregation used by Bila.
} 
result in itself, for at the aggregate level the correlation between hours per worker and employment growth is positive: 0.26 . At the level of the firm, shocks are absorbed mainly along one of the two margins, while at the aggregate level the response to a given shock is shared by both margins. ${ }^{10}$

Lastly, we need to construct estimates of the $z_{i 0}^{1}$ 's. We obtain these from the relation:

$$
z_{i, t}^{1}=z_{i t-1}^{1}-\theta_{i t} \Delta h_{i t},
$$

and the constraint that, for every plant, the sample-average of the deviation immediately after adjustment is equal to a common constant, which without loss of generality we set equal to zero. This leads to the following expressions for $z_{i t}^{1}, z_{i t}, \Delta e_{i t}^{*}, \Delta E_{t}^{*}$ and $v_{i t}$ in terms of observables (the $h_{i t}$ 's and $e_{i t}$ 's): ${ }^{11}$

$$
\begin{aligned}
z_{i, t}^{1} & =\theta_{i t}\left(\bar{h}_{i}-h_{i t}\right) \\
z_{i t} & =z_{i, t}^{1}-\Delta e_{i t} \\
\Delta e_{i t}^{*} & =\Delta e_{i t}+\theta_{i t} \Delta h_{i t} \\
\Delta E_{t}^{*} & =\frac{1}{N} \sum_{i} \Delta e_{i t}^{*} \\
v_{i t} & =\Delta e_{i t}^{*}-\Delta E_{t}^{*},
\end{aligned}
$$

where $\bar{h}_{i}$ is the average (over $t$ ) of the $h_{i t}$ 's and $N$ denotes the number of establishments.

\section{Characterizing Microeconomic Policies and HETEROGENEITY}

In this section we characterize microeconomic policies and the evolution of the crosssectional distribution and its determinants, while in the next one we measure the impact of these factors on agregate dynamics. All the calculations below use a discretized state space. The deviation index $z$ takes values between -7.7 and 8.0 over an equally-spaced grid with partitions of length 0.01 .

Despite our concerns about measurement error when estimating $\theta$, in this section we describe our results as if measurement error played only a secondary role. In Appendix $\mathrm{C}$ we show that most of our findings are robust to "reasonable" assumptions about measurement

\footnotetext{
${ }^{10}$ This is yet another manifestation of how minleading representative agent models can be.

"See Appendix B for the derivations.
} 
error. Moreover, we show that measurement error tends to conceal rather than artificially generate the features we find. That appendix considers two measurement error models. The first (and simplest) assumes i.i.d. (Normal) measurement error on establishment level hours and employment; ${ }^{12}$ the second considers measurement error in employment that generates spurious negative correlation between hours and employment.

We briefly describe four implications - common to both sets of assumptions for measurement error - that should be kept in mind when interpreting the results presented below. ( $m . i)$ If the effective hazard is smooth and increasing, ${ }^{13}$ the minimum value estimated for the effective hazard will be upward biased while the maximum will be (almost) unbiased, It follows that in this case the measured effective hazard will look less increasing than the actual effective hazard. ${ }^{14}$ On the other hand, no bias arises when estimating a constant effective hazard. ( $m . i i$ ) The measured cross sectional distribution and the distribution of idiosyncratic shocks are the convolution of the true distributions and a measurement error. (m.iii) If idiosyncratic shocks are serially uncorrelated, measured idiosyncratic shocks are negatively serially correlated and positively correlated with pre-shock deviations $\left(z^{1}\right)$. The latter correlation decreases as the magnitude of the variance of idiosyncratic shocks increases. ( $m . i v$ ) The distribution of conditional adjustments is a convolution of the true distribution and a (complicated function of) measurement error. The bias in the location of the conditional distributions of adjustments decreases (to zero) as the absolute value of $z$ increases. Measurement error cannot create a spurious spike at zero (no adjustment) nor at -1 (full adjustment); rather it spreads out any spikes.

\subsection{The effective hazard function}

At each point in time, the effective hazard is constructed by dividing by $z$ the average change in employment of those that are at $z$ just before employment adjustments take place for all $z \neq 0$. . $^{15}$

Average effective hazand

Figure 3.1 depicts the average (over quarters) empirical effective hazard - both the

\footnotetext{
${ }^{12}$ Both sources of measurement error (employment and hours) are asumed independent in this case.

${ }^{13}$ An effective hasard in increacing if the fraction of the deviation closed by a firm increases with the absolnte valne of the deviation. Formally this means that $A(x, t)$ is decreacing in $x$ for negative $z$ and increasing for positive $\approx$. The smoothneas requirement is that the effective hasard's derivative be continuous.

"Its estimate will be upward biased for small (abeolute) values of a and clowe to unbiased for large (absolnte) values of $z$.

${ }^{13}$ This highly non-parametric approsch is feavible because of the large data set available; a more efficient, but leas parameter-free approach would be to run a locally linear regrestion of changea in employment against $x$.
} 
actual empirical hazard and the smoothed hazard using a cubic spline are shown. It is apparent from this figure that the empirical effective hazard is increasing with respect to the microeconomic deviations. ${ }^{16}$ As mentioned above, this type of microeconomic nonlinearity is akin to $(S, s)$ type models, and implies that aspects of the cross-sectional distribution of deviations other than its first moment matter for aggregate dynamics. The effective hazard is also fairly symmetric; that is, on average, establishments adjust to positive and negative deviations alike.

The next step is to characterize the evolution of the effective hazard over our sample. Since our data are quarterly and not seasonally adjusted, it is somewhat more revealing to report the path of the hazard in two steps. In the first one we show the seasonal component in isolation, while in the second one we show yearly averages. ${ }^{17}$

\section{Seasonal effective hazard}

The solid lines in the panels of figure 3.2 illustrate the seasonal hazards, while the dashed lines represent the average hazard (over all quarters). ${ }^{18}$ Several conclusions emerge from this figure: First, the effective hazard is clearly increasing and fairly symmetric across all seasons. Second, there is some mild variation across the seasons. For given deviations, there is a higher than average propensity to destroy jobs during the first quarter; the second quarter shows a substantially lower than average propensity to destroy jobs, the third quarter shows slightly higher than average propensity to create and lower propensity to destroy, while the fourth quarter shows lower than average propensities to create and destroy jobs, particularly for establishments with large deviations. These patterns are consistent with the observed seasonal properties of aggregate and idiosyncratic shocks. For example, the second quarter's lower destruction is consistent with the fact that second quarter shocks are more transitory than shocks in other seasons, a fact we document later in the paper. At the same time, aggregate shocks tend to be particularly bad in the second quarter (in our sample, the average aggregate shock during the second quarter is $-4 \%$ while the overall average is $0.1 \%$ ). This latter fact combined with the transitory nature of shocks,

\footnotetext{
${ }^{10}$ Given result (m.i) above, the true effective hazard is likely to be more increasing than that depicted in Figure 3.1.

${ }^{17}$ We report yearly averages rather than quarterly seasonally adjusted hasands to save space. Moat of the relevant information is contained in the figures we present. For visual aid, we also smooth the effective hazard with a cubic spline. In all of the statintical analysis and decompoaition exercises that follow we use the actual rather than the smoothed effective hazard, however. Also, notice that given the nonlinearity of the model, using seasonally adjusted data directly may be lese appropriate than in the case of linear models.

${ }^{18}$ The panel labeled firat quarter in this figure refers to the hasard reflecting the employment changes from the firat to the second quarter; the second quarter refers to the changes from the second to the third quarter; and so on.
} 
implies that during the second quarter the right arm of the hazard should be substantially lower than average, while the left arm may be above or below average.

\section{Cyclical effective hazand}

The solid lines in figure 3.3 depict the annual averages of the quarterly effective hazards. The dashed lines portray the sample average of these hazards. The effective hazard does vary systematically over time. It shifts up from 1972 to 1975 and then shifts down from 1975 through 1979 . The behavior of the hazard around the 1974-75 recession is particularly interesting. The upward shift in the right arm of the effective hazard in both 1974 and 1975 occurred during the sharp downturn in late 1974 and early 1975 . The upward shift in the left arm in 1975 is due to the recovery phase of the $1974-75$ recession. The latter is consistent with the implications of standard search models: the high unemployment rate prevailing at the end of the recession facilitates job creation (conditional on the deviations). ${ }^{19}$

The bottom line of these three figures is clear: The effective hazard is increasing with respect to the magnitude of firms' deviations, it is fairly symmetric, it has a mild procyclical/lower frequency pattern, and a mild seasonal pattern probably linked to the transitory nature of seasonal shocks.

\subsection{The cross-section of employment deviations}

The cross-section of deviations is the endogenous result of aggregate and idiosyncratic shocks filtered by the microeconomic policies. In this subsection we briefly characterize the cross-sectional distribution, and then move on to describe its determinants. At each point in time, the cross-section of deviations is the histogram of deviations $z$.

The average cross-section of deviations is depicted in figure 3.4 (located at the bottom of figure 3.1). Two points are worth making. First, establishments spend a large fraction of their time within plus/minus 30 percent of their target employment level. ${ }^{20}$ Second, the average cross-sectional density is fairly symmetric, reflecting the symmetry of the hazard and the trendless behavior of manufacturing employment over the period considered here.

The solid lines in figure 3.5 show the paths of the mean, standard deviation, skewness

\footnotetext{
${ }^{19}$ To be more precise, quarterly plote of the hazard (not shown) reveal that the big surge in destruction occurs in the fourth quarter of 1974 and the first quarter of 1975 while the increase in creation occurs in the last three quarters of 1975.

${ }^{20}$ Result (m.ii) suggests that the actual crose-section may be leas spread-out than that depicted in Figure 3.4.
} 
and kurtosis coefficients of the cross-sectional density of deviations. ${ }^{21}$ The dashed lines show business cycle clocks, corresponding to linear transformations of aggregate employment growth. This figure shows that there is substantial movement in the different moments of the cross-sectional distribution which, according to equations (2) and (3), suggests that an important component of aggregate dynamics is missed by only looking at the average deviation.

We turn next to the distributions of idiosyncratic shocks and adjustments.

\subsection{The distribution of idiosyncratic shocks}

At each point in time, the density of idiosyncratic shocks is the histogram of the estimated $v_{i, t} \mathrm{~s}$, which correspond to:

$$
v_{i, t} \equiv \Delta e_{i t}-\Delta E_{t}^{*}+\theta_{i t} \Delta h_{i t}
$$

The distribution of idiosyncratic shocks plays an important role in shaping the dynamic response of aggregate employment to aggregate shocks. In addition to a propagation mechanism, changes in the distribution of idiosyncratic shocks may account directly for aggregate employment changes. This is what is typically referred to as "reallocation" shocks. ${ }^{22}$

Reallocation shocks can be the result of changes in higher moments of the distribution of idiosyncratic shocks - including its variance, which is the standard definition of reallocation shocks. They can also reflect more subtle things, such as the presence of serial correlation in idiosyncratic shocks, which would induce correlation between idiosyncratic shocks and the position of firms in state space. We briefly characterize the behavior of some of these factors. The solid lines in figure 3.6 illustrate the paths of the standard deviation and skewness of idiosyncratic shocks, as well as of the correlation between these shocks and $z_{1}$, the deviations at the beginning of the period. ${ }^{23}$ The dashed lines depict business cycle clocks, corresponding to linear transformations of aggregate employment growth.

There is no particular pattern in third moments but a clear increase in the second moment during the $1974-76$ period, including the recession and its recovery, and during

\footnotetext{
${ }^{21}$ To reduce the number of figres we only show seasonally adjusted veraions. The conclusions also hold for the seasonally unadjusted seriea.

${ }^{22}$ Later we expand this definition to include reallocation micro-policy shocks. That is, given exogenous shocks and deviations, eatablishments may choose to create and deatroy more jobs.

${ }^{23}$ In the figure, all series are seasonally adjusted. Non-seasonally adjusted series lead to the same conclusions.
} 
the second oil shock. ${ }^{24}$ There is also a non-negligible positive correlation between $z_{1}$ and idiosyncratic shocks. ${ }^{25}$ This latter correlation fluctuates substantially; for example, it drops dramatically in the downturn in $1975 .^{26}$

\subsection{The distribution of adjustments}

Average distribution of adjustments

Figure 3.7 shows the distribution of adjustments conditional on different ranges for the deviations just before adjustments take place. The $x$-axes correspond to the ratio of actual employment changes, divided by $z .^{27}$

Three observations stand out: First, there is always a mode at zero; ${ }^{28,29}$ indicating that a large number of establishments choose not to adjust, even in circumstances where their deviations are large. This evidence supports the hypothesis that there is a non-convexity in the adjustment technology of individual establishments. Second, as the deviations get large, a second mode emerges at minus one. ${ }^{30}$ This reflects two aspects of the establishments' adjustment technologies: (a) the effective hazard is increasing, which explains why the second mode emerges more clearly for large deviations, ${ }^{31}$ and (b) lumpy and complete adjustments are frequent among firms with large deviations, which suggests increasing returns in the adjustment technologies. And third, although there is substantial dispersion in the distribution of adjustments, the majority of plants adjust in the direction and within the range indicated by the model.

\section{PUtTing things TOgether: AggRegate EMPlOYMENT FLUCTUATIONS (NET FLOWS)}

In this section we change the metric. Instead of describing the behavior of the different factors considered above directly, we describe them in terms of their contribution to aggregate employment fluctuations. We proceed in four steps: First, we decompose fluctuations

\footnotetext{
${ }^{24}$ Reault (m.iii) implies that the eatimated values of the variance of idionyncratic shocks may be biased upwards. This bias has no effect on the pattern of this series.

${ }^{25}$ Result (m.iii) anggeate that mearurement error may be responsible for this.

${ }^{28}$ In the presence of measurement exror, this finding is consistent with there being no correlation between $v$ and $x^{1}$. This follows from the fact that the largest variance of idiosyncratic shocks occurred around 1975 and result (m.iii).

${ }^{27}$ Remember that a negative $x$ denotes a shortage of employment.

${ }^{28}$ By zero we mean changes in employment of leas than 5 percent of the deviations.

${ }^{29}$ Result (m.iv) implies that this finding is robust to meaurement error.

${ }^{30}$ Result ( $m . i v$ ) shows that this finding is not due to meavurement error.

${ }^{31}$ See reault (m.iv).
} 
in aggregate employment into those that are due to changes in the effective hazard and those that are due to changes in the cross-sectional distribution of deviations. Second, we split changes in employment due to changes in the cross sectional distribution into those that correspond to reallocation and to aggregate shocks. Third, we split changes in employment due to changes in the effective hazard into those that correspond to reallocation and to aggregate microeconomic-policy-fluctuations. And fourth, we assess the impact of the nonlinear nature of the effective hazard on the response of employment growth to aggregate shocks.

\subsection{Employment fluctuations due to changes in the effective hazard and cross-sectional distribution}

In this subsection we decompose changes in aggregate employment into those that are due to fluctuations in (a) the effective hazard and (b) the cross-sectional distribution of deviations. The components we wish to consider not only interact with each other, but they do so in a highly non-linear fashion. Anything reminiscent of an Analysis of Variance is therefore very difficult.

We have chosen the following strategy: Let $A(z, t), A(z)$ and $A^{\bullet}(z, t)$ denote the actual, overall average and seasonal average (i.e., a different average for each season) effective hazards, respectively. Similarly, let $f(z, t), f(z)$ and $f^{\prime}(z, t)$ denote the actual, overall average and seasonal average cross-sectional density of deviations immediately prior to adjustment. It is now possible to construct the aggregate employment changes associated to each possible combination of effective hazard and cross-sectional density described above by substituting $A(z, t)$ and $f(z, t)$ in equation (2) by the appropriate combination:

$$
\Delta E_{t}^{f}=-\int z A(\cdot) f(\cdot) d z .
$$

Thus, for example, the aggregate employment growth series implied by allowing for seasonal variations in the effective hazard and no variation in the cross-sectional density is: $\Delta E_{t}^{f}=$ $-\int z A^{*}(z, t) f(z) d z$.

To measure the proximity between the aggregate series constructed above and the actual employment growth series we use the standard $R^{2}$ goodness-of-fit measure: ${ }^{32}$

$$
R^{2} \equiv 1-\frac{\sigma^{2}\left(\Delta E^{f}-\Delta E\right)}{\sigma^{2}(\Delta E)}
$$

\footnotetext{
${ }^{32}$ We note that this $R^{2}$ is not bounded from below by sero since there is no restriction of a zero covariance between the predictions and residuals generated from these exercises.
} 
Table 1: Decomposition of Aggregate Employment Fluctuations

\begin{tabular}{|l|ccc|}
\hline & \multicolumn{3}{|c|}{$R^{2}$} \\
& $A(z)$ & $A^{*}(z, t)$ & $A(z, t)$ \\
\hline$f(z)$ & 0.00 & 0.09 & 0.47 \\
$f^{s}(z, t)$ & 0.03 & 0.16 & 0.51 \\
$f(z, t)$ & 0.77 & 0.90 & 1.00 \\
\hline
\end{tabular}

It follows from Table 1 that changes in the cross-section distribution of deviations have more impact on aggregate employment than variations in the effective hazard. From the entry $(2,2)$ of Table 1 , we infer that seasonal changes (in both the hazard and the crosssection) account for 16 percent of fluctuations in employment; we are interested in splitting the remaining 84 percent between cyclical fluctuations in both sources. The last column of Table 1 shows that when the actual effective hazard is used, 58 percent (49/84) of aggregate employment fluctuations (not explained by seasonal effects) is accounted for by going from the seasonal to the actual cross sectional distribution. And from the other end, the last row reflects that about 88 percent (74/84) of aggregate employment fluctuations can be explained without the need of cyclical fluctuations in the effective hazard. ${ }^{33}$ Thus, changes in the cross sectional distribution account for at least 60 percent and as much as 90 percent of fluctuations in employment growth. Given our decomposition, the remainder is due to changes in the effective hazard.

The large importance of changes in the cross sectional distribution relative to that of changes in microeconomic policies is even more apparent once we plot the actual path of employment versus that which results from removing cyclical fluctuations in the effective hazard. Figure 4.1a does so, using a solid line for the former and a dashed line for the latter. 34

Figure $4.1 \mathrm{~b}$ highlights a fact that is otherwise hidden in figure $4.1 \mathrm{a}$ by the magnitude of the 1974-75 recession. By reporting the employment changes corresponding to the first row of the tables -i.e. by removing the fluctuations in the cross-sectional distributionone can see from Figure 4.1b that the change in the effective hazard did affect (negatively) the downturn and (positively) the recovery phase of the recession as well as the response

\footnotetext{
${ }^{33}$ To obtain this number we first compute the contribution of hazard fluctuations, which is $(1.00-0.90) / .84$. The contribution of the crosestion distribution is the complement of this.

${ }^{34}$ In all of the remaining figures (4.1-5.1), the labeling of the quarterly tick marks on the horizontal axis is such that the depicted growth ratea refiect the forward rate of change. For example, the growth rate of employment at the tick mark for 1974:4 reflects the employment change from the midpoint of the fourth quarter of 1974 to the midpoint of the first quarter of 1975.
} 
of the economy to the second oil shock. This systematic effect may be reflecting some form of specification error in our equation measuring deviations, or it can also reflect true changes in policy due to the role of omitted cyclical variables in microeconomic policies; in particular, section 3 documented the upward shift on the creation side of the hazard during the recovery phase of the 1974-75 recession, which is consistent with the implications of models where matching costs are decreasing with respect to the unemployment rate.

\subsection{Decomposing employment fluctuations due to changes in the cross- sectional distribution}

It is apparent from the previous subsection that, given the shape of the effective hazard, the primary factor for understanding aggregate employment fluctuations lies in understanding the main factors driving the cross-sectional distribution; this is the focus of this section. ${ }^{35}$ It is important to notice that the discussion below is conditional on the path of the effective hazard, while in the next section we decompose the effects of fluctuations in this hazard.

\section{Aggregate versus reallocation shocks}

Our procedure is well suited to shed light on the debate about the relative importance of aggregate versus reallocation shocks for aggregate employment fluctuations. ${ }^{36}$

Figure 3.6 suggests that the path of the standard deviation of idiosyncratic shocks is highly correlated with aggregate shocks. Indeed, this is the case: the correlation between

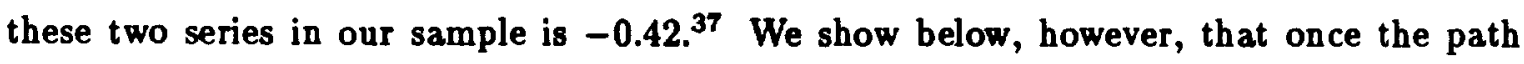
of the distribution of idiosyncratic shocks is filtered through the cross-section of deviations and effective hazard functions, reallocation shocks have almost no impact on aggregate net employment fluctuations. 38

\footnotetext{
${ }^{35}$ It is very important to dintinguinh between the statement that finctuations in the effective haxard do not matter 100 much for arerezate employment fuctuations, which is what we showed in the previous section, from the erroneom statement that the ahape of the effective hasard does not matter for aggregate employment dyamion. See section 4.4 and Caballero and Engel $(1992,1993)$ for evidence on the important role of increasing hasards on ageregate employment dynamics.

${ }^{30}$ See e.g. Lilien (1982) and Abraham and Katz (1986).

${ }^{37}$ This large negative correlation points to one of the difierences in methodology between that used here and in related literature on the identification of aggregate and reallocation shocks. In Blanchard and Diamond $(1989,1990)$ and Davis and Haltiwager $(1990,1994)$, aggregate and reallocation shocks are identified in part through the asamption of a zero covariance between the two types of shock. Interestingly, in spite of this, these other studies aleo find a small role for reallocation shock in acconnting for busineso cycle fuctuations in employment growth and unemploymeat at short forecast horizons.

${ }^{38}$ It is important to emphasize that this does not imply that the proceas of reallocation is unimportant in accounting for aggregate fluctuations. The interaction of the nonlinear micro policies and the crose-sectional heterogeneity with the aggregate shocks yields rich endogenons dynamics of reallocation over the course of
} 
In order to determine the impact of changes in the distribution of idiosyncratic shocks on aggregate fluctuations, we find the cross-sectional distribution that would have resulted immediately before firms adjust - $f(z, t)$ in the notation of equation (2) - under a variety of assumptions for the distribution of idiosyncratic shocks, and then compute the corresponding changes in employment. We perform two types of experiments for each of these scenarios: (i) pseudo-static and (ii) dynamic. For the former, in the notation of equation (6), we consider the actual $f_{1}(z, t)$ and substitute the distribution of idiosyncratic shocks by various expressions to capture the impact on aggregate fluctuations of changes in the distribution of idiosyncratic shocks. For the dynamic experiment, we take $f_{1}(z, 1)$ as given, but then use equations (6) and (7), together with the actual conditional distributions of adjustments and the corresponding distributions of idiosyncratic shocks, to generate the sequence of cross-sectional distribution of deviations. The advantage of the dynamic approach is that we can look at cumulative effects; its disadvantage is that the effect of auxiliary assumptions and measurement error also accumulate.

Since equations (6) and (7) define identities, both elements in the first row of Table 2 should be equal to one in the absence of rounding errors and approximations; the numbers obtained indicate that approximations have a negligible effect. ${ }^{39}$ The first column of Table 2 summarizes the pseudo-static results. The second and third row replace the actual crosssection distribution of idiosyncratic shocks by its seasonal and overall average, respectively. The conclusion we obtain from these rows is clear: conditional on the path of the effective hazard, practically all the fluctuations in the cross-sectional distribution that are responsible for aggregate employment fuctuations are directly attributable to aggregate rather than reallocation shocks.

Figure 4.2 provides an even starker illustration of the main finding reported in this section. It shows that the aggregate employment growth series obtained by shutting down seasonal and cyclical fluctuations in the distribution of idiosyncratic shocks is almost indistinguishable from the actual employment growth series.

Essentially the same results are obtained with the dynamic experiments, where only the initial cross section distribution is taken as given. The last column of table 2 is the dynamic counterpart of the first column. Again, abstracting away from the correlation between

the cycle. The idea that aggregate shocks endogenously change the timing of reallocation has been the recent focus in the theoretical literature examining the connection between busines cycles and the process of reallocation (see, e.g., Blanchard and Diamond (1990), Caballero and Hammour (1994a,b), Caballero (1992), Davis and Haltiwanger (1990), Hall (1991), Mortensen (1992), Mortensen and Pissarides (1992)).

${ }^{39}$ The slightly larger error in the dynamic exercise is not surprising, since error accumulate only in this case. 
Table 2: Decomposition of Aggregate Employment Fluctuations: Reallocation Shocks

\begin{tabular}{|l|c|c|}
\hline & $\begin{array}{c}\text { pseudo-static } \\
R^{2}\end{array}$ & $\begin{array}{c}\text { dynamic } \\
R^{2}\end{array}$ \\
\hline$g(v, t \mid z)$ & 1.00 & 0.99 \\
$g(v, s \mid z)$, s.a. & 0.95 & 0.94 \\
$g(v \mid z)$, s.u. & 0.94 & 0.92 \\
\hline
\end{tabular}

idiosyncratic shocks and the initial deviations, reallocation shocks play no meaningful role on aggregate net employment fluctuations.

\subsection{Decomposing employment fluctuations due to changes in the effec- tive hazard}

The previous section decomposed about three quarters ${ }^{40}$ of aggregate employment fluctuations into aggregate and reallocation shocks. In this section we decompose the remainder into reallocation and aggregate microeconomic policy shocks. One important obstacle to do so, is that contrary to the case of fluctuations in the cross sectional distribution, the model discussed in section 2 offers no natural way to identify reallocation and aggregate shocks. Moreover, it is not unlikely that a large fraction of these fluctuations simply correspond to specification error resulting from, among other things, omitted state variables. In spite of this, we adopt the following simple convention: We associate reallocation microeconomic policy shocks to symmetric shifts in the effective hazard relative to the seasonally adjusted average hazard.

Based on the above convention, at any point in time, there is a unique decomposition of the non-seasonal component of the effective hazard, $A(z, t)-A^{\prime}(z, t)$, into the sum of reallocation, $R(z, t)$, and aggregate, $P(z, t)$, components: ${ }^{41,42}$

$$
\begin{aligned}
R(z, t)+P(z, t) & \equiv A(z, t)-A^{\prime}(z, t) \\
R(z, t) & \equiv \frac{1}{2}\left[A(z, t)+A(-z, t)-A^{\prime}(z, t)-A^{\prime}(-z, t)\right]
\end{aligned}
$$

\footnotetext{
${ }^{10}$ Strictly speaking, between 60 and 90 percent.

${ }^{11} A^{\bullet}(z, t)$ was specified earlier. It is obtained by averaging $A(x, t)$ over the time periods corresponding to seacon s.

${ }^{42}$ The following decomponition is based on the fact that any function of real variable taking real values, $g(x)$, can be decomposed in a unique way into the sum of an even, $g_{0}(x)$, and an odd, $g_{0}(x)$, with $g_{e}(x)=$ $\frac{1}{2}(g(x)+g(-x))$ and $g_{0}(x)=\frac{1}{2}(g(x)-g(-x))$.
} 
Applying the above decomposition we obtain rather stark results: Starting from the last row of table 1 , we can ask how much does $R^{2}$ increase by adding the reallocational component, $R(z, t)$, to the seasonal hazard: the answer is less than 0.01 . Alternatively, we can ask how much does $R^{2}$ increase by adding the aggregate component, $P(z, t)$, to the seasonal hazard: the answer is 0.09 . Thus, aggregate shocks account for more than ninety percent of the employment fluctuations arising from changes in the effective hazard.

Combining these results with those in the previous subsection yields an estimate of the total contribution of aggregate and reallocation shocks. The contribution of reallocation shocks is clearly small. Recomputing the last row of the static exercise in table 2, now removing reallocation hazard shocks, we obtain an $R^{2}=0.93$, while recomputing the second row (also removing reallocation hazard shocks) yields an $R^{2}=0.95$. Figure 4.3 illustrates the actual path of employment growth (solid line) and the path of the same variable when both sources of reallocation shocks (idiosyncratic shocks to desired employment and symmetric shifts in microeconomic policies) are removed (dashed line). The conclusion is quite clear: aggregate shocks are the main contributor to net employment fluctuations in our sample.

\subsection{How much are higher moments adding?}

Caballero and Engel $(1992,1993)$ and section 2 show that non-constant (over $z$ ) effective hazards imply that properly specified aggregate equations should include higher moments of the cross-sectional distribution of deviations on the right hand side. In terms of the noncentral moments of the cross-sectional distribution just before adjustments take place (i.e. after the idiosyncratic and aggregate shocks of the period), we have: ${ }^{43}$

$$
\Delta E_{t}=-\sum_{i=0}^{K} \lambda_{i} M_{z}^{(i+1)}(t) .
$$

Table 3 reports the results for different values of $K$. Column 1 corresponds to $K=0$, which is the standard partial adjustment model. 4 The fit is good, $R^{2}=0.68$, but this is not surprising since $M_{z}^{(1)}(t)$ includes the current aggregate shock which is the primary driving force for current aggregate employment changes.

\footnotetext{
${ }^{43}$ Here we disregard fluctuations in the effective hasard.

${ }^{44}$ For this, note that $M_{z}^{(1)}(t) \equiv-\left(E_{t}^{*}-E_{t-1}\right)$. Note, however, that ance $M_{z}^{(1)}(t)$ already includes the current aggregate shock, running equation (12) yieldo a partial adjustment model that uses more information than the atandard aggregate time series version of it. Indeed, the reaidual of this equation has no interpretation in terms of aggregate shocks. Rather, it corresponds to measurement and specification error.
} 
More interesting is the fact reported in columns 2 and 3: in spite of the relatively fast adjustment, it is still possible to detect in aggregate data a role for higher moments of the cross sectional distribution. Estimating a symmetric quadratic hazard model $(K=2$ and $\lambda_{1}=0$ ) and a more general model with $K=5$, brings the $R^{2}$ up to 0.76 and 0.82 , respectively. Such changes in $R^{2}$ correspond to reductions in mean square error (MSE) of 28 and 45 percent, respectively.

\section{Putting things together: fluctuations in gross flows}

Net aggregate employment changes result from the actions of many heterogeneous establishments. A particular grouping of these actions is by whether these convey increments or reductions of employment at the corresponding establishments. This is what Davis and Haltiwanger (1992) describe as job creation and destruction. Our framework is well suited for analyzing this decomposition; a non-constant hazard, combined with movements in the cross-sectional distribution of deviations, can yield rich and far from perfectly correlated lives to both creation and destruction. This richness is necessary to match the behavior of job flows in U.S. manufacturing.

Figure 5.1 depicts the job creation and destruction series for our sample. The general features of these series are similar to those found by Davis and Haltiwanger for the entire manufacturing sector. Quarterly job creation and destruction rates both average close to 5 percent. Job destruction is much more cyclically sensitive than job creation. The time series variance of job destruction is more than three times larger than the variance of job creation.

As before, $A(z, t), A(z)$ and $A^{\prime}(z, t)$ denote the actual, overall average and seasonal average of the effective hazard, respectively. And $f(z, t), f(z)$ and $f^{s}(z, t)$ denote the actual, overall average and seasonal average cross-sectional density of deviations immediately prior to adjustment. It is now possible to construct aggregate job creation and destruction associated to each possible combination of effective hazard and cross-sectional density:

$$
\begin{aligned}
& J C_{t}^{f}=-\int_{-\infty}^{0} z A(\cdot) f(\cdot) d z, \\
& J D_{t}^{f}=-\int_{0}^{\infty} z A(\cdot) f(\cdot) d z .
\end{aligned}
$$

Similarly, by replacing $f(z, t)$ by the cross-sectional density resulting from different assumptions about the distribution of idiosyncratic shocks (in both, pseudo-static and dynamic 
Table 3: Aggregate Regressions with Higher Moments

\begin{tabular}{|c|c|c|c|}
\hline & $K=0$ & $K=2$ & $K=\overline{5}$ \\
\hline$-M_{z}^{(1)}$ & $\begin{array}{c}0.445 \\
(0.053)\end{array}$ & $\begin{array}{c}0.419 \\
(0.048)\end{array}$ & $\begin{array}{c}0.337 \\
(0.086)\end{array}$ \\
\hline$-M_{z}^{(2)}$ & - & - & $\begin{array}{c}0.010 \\
(0.258)\end{array}$ \\
\hline$-M_{z}^{(3)}$ & - & $\begin{array}{c}0.103 \\
(0.032)\end{array}$ & $\begin{array}{c}0.364 \\
(0.116)\end{array}$ \\
\hline$-M_{z}^{(4)}$ & - & - & $\begin{array}{c}0.013 \\
(0.042)\end{array}$ \\
\hline$-M_{z}^{(5)}$ & - & - & $\begin{array}{c}-0.008 \\
(0.003)\end{array}$ \\
\hline$-M_{z}^{(\boldsymbol{\theta})}$ & - & - & $\begin{array}{c}-0.001 \\
(0.001)\end{array}$ \\
\hline$R^{2}$ & 0.68 & 0.76 & 0.82 \\
\hline $\bar{R}^{2}$ & 0.67 & 0.74 & 0.78 \\
\hline MSE/MSE(1) & 1.00 & 0.72 & 0.55 \\
\hline$D W$ & 1.95 & 2.29 & 1.97 \\
\hline
\end{tabular}

All regressions include a constant. Standard errors in parentheses. 
experiments) it is possible to assess the importance of reallocation shocks for the time series behavior of job creation and destruction.

\subsection{Job creation}

Table 4 decomposes fluctuations in job creation into microeconomic policy (effective hazard) and cross-sectional distribution driven fluctuations. Abstracting from seasonal effects, changes in the cross-sectional distribution and changes in microeconomic policy fluctuations are about equally important in accounting for fluctuations in job creation. ${ }^{45}$

Table 4: Decomposition of Fluctuations in Job Creation

\begin{tabular}{|l|ccc|}
\hline & \multicolumn{3}{|c|}{$R^{2}$} \\
& $A(z)$ & $A^{3}(z, t)$ & $A(z, t)$ \\
\hline$f(z)$ & 0.00 & 0.30 & 0.66 \\
$f^{\prime}(z, t)$ & 0.13 & 0.36 & 0.67 \\
$f(z, t)$ & 0.54 & 0.77 & 1.00 \\
\hline
\end{tabular}

Table 5 shows the relative importance of reallocation shocks for fluctuations in job creation due to changes in the cross sectional distribution of deviations. The first column describes the results within the pseudo-static scenario while the second column does so within the dynamic scenario. Comparing the first and last rows reveals that about 25 percent of fluctuations in job creation can be directly accounted for by reallocation shocks in the static case and 21 percent in the dynamic case. ${ }^{46}$

Table 5: Decomposition of Fluctuations in Job Creation: Reallocation Shocks

\begin{tabular}{|l|c|c|}
\hline & $\begin{array}{c}\text { pseudo-static } \\
R^{2}\end{array}$ & $\begin{array}{c}\text { dynamic } \\
R^{2}\end{array}$ \\
\hline$g(v, t \mid z)$ & 1.00 & 0.95 \\
$g(v, s \mid z)$, s.a. & 0.89 & 0.87 \\
$g(v \mid z)$, s.u. & 0.75 & 0.79 \\
\hline
\end{tabular}

As for effective hazard fluctuations, we find substantially more role for reallocation shocks than in the case of net employment changes: Starting from the last row of table 4,

\footnotetext{
${ }^{45}$ Changes in microeconomic policies account for between 51 and 53 percent of aggregate fluctuations not explained by seasonal effects.

${ }^{16}$ A bout half of the contribution of reallocation shocks is sesociated with seasonal effects.
} 
we find that $R^{2}$ increases by 0.13 when $R(z, t)$ is added to the seasonal hazard, while $R^{2}$ only increases by less than 0.01 when $P(z, t)$ is added to the seasonal hazard. These results suggest that over 50 percent, and as much as 96 percent, of fluctuations in job creation driven by fluctuations in microeconomic policies is due to reallocation shocks.

Combining the results above we can estimate the total contribution of aggregate and reallocation shocks. Starting from the last row of the static exercise in table 5 , if we also remove reallocation hazard shocks, we obtain an $R^{2}=0.36$, while starting from the second row yields an $R^{2}=0.60$. Thus, reallocation shocks seem to be slightly more important than aggregate shocks for fluctuations in job creation.

\subsection{Job Destruction}

Table 6 decomposes fluctuations in job destruction into microeconomic policy and crosssectional distribution driven fluctuations. The results are similar to those for net employment changes; the bulk of fluctuations in job destruction is explained by changes in the cross sectional distribution of deviations. Abstracting from seasonal effects, changes in microeconomic policies explain between 10 and 50 percent of fluctuations in job destruction.

Table 6: Decomposition of Fluctuations in Job Destruction

\begin{tabular}{|l|ccc|}
\hline & \multicolumn{3}{|c|}{$R^{2}$} \\
& $A(z)$ & $A^{*}(z, t)$ & $A(z, t)$ \\
\hline$f(z)$ & 0.00 & -0.02 & 0.48 \\
$f^{\prime}(z, t)$ & -0.01 & 0.05 & 0.52 \\
$f(z, t)$ & 0.82 & 0.89 & 1.00 \\
\hline
\end{tabular}

Table 7 shows the role of reallocation shocks for fluctuations in job destruction due to changes in the cross sectional distribution of deviations. The first column describes the results within the pseudo-static scenario while the next column does so within the dynamic scenario. Conclusions are similar to those for net employment changes. Comparing the first and last rows reveals that about 8 percent of job destruction fluctuations can be directly accounted for by reallocation shocks in the static case and 11 percent in the dynamic cases. ${ }^{47}$

As for effective hazard fluctuations, we find more role for reallocation shocks than in the case of net employment changes: Starting from the last row of table 6, we find that $R^{2}$

\footnotetext{
${ }^{17}$ Virtually all of the contribution of reallocation shocks is asociated with seasonal effects.
} 
Table 7: Decomposition of Fluctuations in Job Destruction: Reallocation Shocks

\begin{tabular}{|l|c|c|}
\hline & pseudo-static & dynamic \\
& $R^{2}$ & $R^{2}$ \\
\hline$g(v, t \mid z)$ & 1.00 & 1.00 \\
$g(v, s \mid z)$, s.a. & 0.93 & 0.90 \\
$g(v \mid z)$, s.u. & 0.92 & 0.89 \\
\hline
\end{tabular}

increases by 0.06 when $R(z, t)$ is added to the seasonal hazard, and by 0.10 when $P(z, t)$ is added to the seasonal hazard. These results suggest that between 10 and 50 percent of fluctuations in job destruction driven by fluctuations in microeconomic policies is due to reallocation shocks.

Combining the results above we can estimate the total contribution of aggregate and reallocation shocks. Starting from either the second or third row of the static exercise in table 7, if we remove reallocation hazard shocks we obtain an $R^{2}=0.92$. Thus, reallocation shocks account for about 10 percent of fluctuations in job destruction.

\section{Conclusion}

In this paper we used a balanced panel of large plants in U.S. manufacturing industries to study microeconomic employment adjustment and its aggregate implications. We used these data to retrace the steps suggested by the literature on aggregation of $(S, s)$-type models, and in particular, to construct the path of the cross sectional distribution of deviations between actual and desired employment, as well as the histograms of average adjustments (effective hazards) at each point in time.

The microeconomic evidence is clearly supportive of the basic implications of $(S, s)$-type models: ${ }^{43}$ substantial inaction, lumpy adjustments, and increasing effective hazard (i.e. the expected fraction of the deviations bridged is an increasing function of the magnitude of the deviations).

But we went beyond characterizing microeconomic policies and used these policies in conjunction with our estimates of the cross sectional distributions of deviations and idiosyncratic shocks to study the contribution of several factors to aggregate employment fluctuations. Doing so, we concluded that fluctuations in the cross sectional distribution

\footnotetext{
${ }^{48}$ See Hamermesh (1989) for an intereating case study documenting microeconomic lumpineas in employment adjustments.
} 
of deviations rather than in microeconomic policies accounted for the bulk of aggregate employment fluctuations during our sample period (1972:1-1980:4). Perhaps more interestingly, we found that very little of the fluctuations in the cross sectional distributions that are reflected in aggregate employment fluctuations can be attributed directly to reallocation shocks.

This does not mean that idiosyncratic shocks are small, that they do not matter for aggregate employment fluctuations, or that their distribution does not vary over time (reallocation shocks). Quite the contrary, by far the dominant source of microeconomic employment changes is idiosyncratic shocks, these play a key role in mapping aggregate shocks into actual employment responses, and the second moment of the distribution of these shocks is clearly countercyclical. However, the latter fluctuations, once filtered by the interplay between microeconomic policies and cross sectional heterogeneity, turn out to play only a minor role in aggregate net employment fluctuations.

We also studied gross employment flows and found a larger role for reallocation shocks, especially for job creation. 


\section{APPENDICES}

\section{A. Data Appendix}

The analysis in this paper is conducted using the Longitudinal Research Database (the LRD). The LRD is a comprehensive probability sample of establishments in U.S. manufacturing industries. An establishment is defined as a single physical location engaged in manufacturing activity. The LRD sampling frame encompasses all U.S. manufacturing establishments with five or more employees. These establishments account for more than 99 percent of manufacturing employment.

The LRD is based upon the quinquennial Census of Manufactures (CM) and the Annual Survey of Manufactures (ASM). The LRD currently contains CM data for 300,000-400,000 plants in each year 1963,1967,1972,1977, 1982, and 1987 and ASM data for a probability sample of 50,000-70,000 plants in each year from 1972 to 1988. ASM panels are selected from the manufacturing universe identified by the $C M$, commence two years after the $C M$, and continue for five years. All large establishments (approximately 250 employees or more) are in each ASM panel while plants with 5-249 employees are included in the ASM panel with probabilities that increase with size. This implies that most small establishments are not in consecutive ASM panels. New establishments are added to the panel as it ages to incorporate births and to preserve the panel's representative character. For further information regarding the properties of the LRD sample, see Davis, Haltiwanger and Schuh (1994).

Employment data in the form of total employment (annual only), production worker employment, and total production worker hours are available at annual and quarterly frequencies for each plant. This study exploits the quarterly production worker employment and total production worker hours data. Quarterly production worker employment data are available for payroll periods covering the 12th day of February, May, August, and November. 19 Quarterly production worker hour data reflect total hours by all production workers for each quarter (January-March, April-June, July-September, October-December). The total hours are all hours worked or paid for, except hours paid for vacations, holidays, or sick leave. Note that the observation on the number of production workers per quarter represents the midpoint of each quarter for which we measure total production worker hours.

\footnotetext{
195ee Davis, Baltiwanger, and Schuh (1994) for the procedure used to convert the March data on the number of production workers in the original file to an estimate of the February number.
} 
The sample used for this study are all continuously operating establishments from 1972 to $1980 .^{50}$ Specifically, all establishments with positive hours and positive employment in all quarters from 1972 to 1980 . The resulting sample size is 10025 which represents between $1 / 5$ and $1 / 7$ of all of the establishments in the ASM. Since we have selected only continuously operating establishments for the entire $1972-80$ period, this implies that our sample is essentially the large, continuing establishments. Recall that small establishments (less than 250 employees) are typically not in consecutive ASM panels. Accordingly, the typical establishment in our sample is much larger than the typical establishment from a representative sample. In 1977 , for example, the average establishment size in our sample is $\mathbf{5 8 9}$ workers while for all plants the average establishment size is $\mathbf{5 8 .}$

While our sample is not representative, the establishments in our sample constitute approximately $33 \%$ of total manufacturing employment in a typical quarter. Further, the time series properties of the quarterly growth rate of production worker employment for all plants and the growth rate of production worker employment for our sample are very similar. For the sample period $1972: 1$ to $1980: 4$, the mean quarterly growth rate for all plants is 0.00056 while for our sample the mean is $\mathbf{0 . 0 0 0 5 2}$, the time series standard deviation for all plants is $\mathbf{0 . 0 2 3 1}$ while for our sample it is $\mathbf{0 . 0 2 3 4}$, and the correlation between the growth rate for all plants and the growth rate from our sample is 0.89 .

The analysis in the paper uses the number of production workers to generate quarterly establishment level employment growth rates. Quarterly hours per worker are computed as total production worker hours divided by the number of production workers.

\section{B. Data Construction Appendix}

In this appendix we provide a derivation for the expressions for the theoretical constructs described in section 2 in terms of observable quantities (the $h_{i t}$ and the $e_{i t}$ ). We derive the following expressions, mentioned at the end of that section:s1

$$
\begin{aligned}
z_{i, t}^{1} & =\theta_{i t}\left(\bar{h}_{i}-h_{i t}\right) \\
z_{i t} & =z_{i, t}^{1}-\Delta e_{i t} \\
\Delta e_{i t}^{*} & =\Delta e_{i t}+\theta_{i t} \Delta h_{i t} \\
\Delta E_{i}^{*} & =\frac{1}{N} \sum_{i} \Delta e_{i t}^{*} \\
v_{i t} & =\Delta e_{i t}^{*}-\Delta E_{t}^{*} .
\end{aligned}
$$

\footnotetext{
${ }^{30}$ We stop our sample period in 1980:4 because quarterly total production worker hours are imputed (i.e., not collected) for all eatablishments beginning in 1981 in non-Census years.

${ }^{31}$ See section 2 for definitions and notation.
} 
We begin by noting that, by definition:

$$
\begin{aligned}
& z_{i t}=z_{i t-1}^{1}-\Delta e_{i t}^{*}, \\
& z_{i, t}^{1}=z_{i t}+\Delta e_{i t} .
\end{aligned}
$$

We also have the expression which links deviations to hours-week: ${ }^{52}$

$$
\Delta e_{i t}^{*}=\Delta e_{i t}+\theta \Delta h_{i t}
$$

where, for notational simplicity, we omit subindices for $\theta$.

Given the expressions in (18), (19) and (20) and the definitions introduced in section 2, we see that the only expression that requires a non-trivial derivation is (13). We derive it next.

Substituting $z_{i t}$ in (19) by the expression in (18), and substituting $\Delta e_{i t}^{*}$ by the expression in (20), leads to:

$$
z_{i, t}^{1}=z_{i t-1}^{1}-\theta \Delta h_{i t}
$$

Applying this expression recursively leads to:

$$
z_{i t}^{1}=z_{i 0}^{1}-\theta\left(h_{i, t}-h_{i 0}\right)
$$

Using the above expression to impose $\sum_{t=0}^{r} z_{i t}^{1}=0$ we obtain:

$$
z_{i 0}^{1}=\theta\left(\bar{h}_{i}-h_{i, 0}\right)
$$

Substituting this expression in (21) leads to (13).

\section{Measurement Error Appendix}

We consider two models of measurement error. In Model 1 we assume that:

$$
\begin{aligned}
& \epsilon_{i t}^{0}=\epsilon_{i t}+\epsilon_{i t}^{e}, \\
& h_{i t}^{0}=h_{i t}+\epsilon_{i t}^{h},
\end{aligned}
$$

where the superscript ${ }^{\circ}$ denotes the "observed" values of the corresponding variable, the $\epsilon_{i t}^{e}$ 's are i.i.d. Normal with zero mean, the $\epsilon_{i i}^{h}$ 's also are i.i.d. Normal with zero mean, and the $\epsilon_{i t}^{e}$ 's and $\epsilon_{i t}^{h}$ 's are independent.

\footnotetext{
${ }^{52}$ See section 2.
} 
In Model 2 we take into account that measurement errors in employment are likely to generate spurious negative correlation between hours and employment since our measure of hours-week is computed by dividing total hours by employment. This model assumes that: ${ }^{53}$

$$
\begin{aligned}
& e_{i t}^{o}=e_{i t}+w_{i t}, \\
& h_{i t}^{\circ}=h_{i t}-w_{i t},
\end{aligned}
$$

where the $w_{i t}$ 's are i.i.d. Normal with zero mean. ${ }^{34}$

Next we consider the main issues raised in section 3 .

\section{Estimates of employment deviations}

From Appendix B and (22), (23), (24) and (25) we have that:

$$
z_{i t}^{o}= \begin{cases}z_{i t}-\theta \epsilon_{i t}^{h}-\Delta \epsilon_{i t}^{e} & \text { for Model 1, } \\ z_{i t}+(\theta-1) w_{i t}+w_{i, t-1} & \text { for Model } 2\end{cases}
$$

It follows that the observed distribution of $z$ is a convolution of the true distribution and a zero mean distribution determined by measurement error.

Denoting by $\operatorname{Var}\left(x_{t}\right)$ the sample variance of the $x_{i t}$ 's (where $x$ is a generic variable), we have that:

$$
\operatorname{Var}\left(z_{t}^{\mathrm{o}}\right)= \begin{cases}\operatorname{Var}\left(z_{t}\right)+\theta^{2} \sigma_{e, h}^{2}+2 \sigma_{e, e}^{2} & \text { for Model 1, } \\ \operatorname{Var}\left(z_{t}\right)+\left[1+(\theta-1)^{2}\right] \sigma_{w}^{2} & \text { for Model 2, }\end{cases}
$$

where the $\sigma^{2}$ terms are evident.

Proceeding in a similar way for the $z_{i t}^{1}$ 's we also conclude that the observed distribution is a convolution of the actual distribution with a zero mean distribution that is a linear function of measurement error, and obtain:

$$
\operatorname{Var}\left(z_{t}^{1,0}\right)= \begin{cases}\operatorname{Var}\left(z_{t}^{1}\right)+\theta^{2} \sigma_{e, h}^{2} & \text { for Model 1, } \\ \operatorname{Var}\left(z_{t}\right)+\theta^{2} \sigma_{w}^{2} & \text { for Model } 2\end{cases}
$$

It follows that the observed series of $z_{i t}$ 's and $z_{i t}^{1}$ 's will be more spread out than the

\footnotetext{
${ }^{33}$ Recall that all variables are in loge.

${ }^{54}$ The normality asoumption can be relaxed to asuming a ammetric distributions for errors, the i.i.d. assumption could also be relaxed to allow for weak dependence, both scrose firms or for a given firm over time. This also holds for Model 1.
} 
actual series. The variance increases somewhat less for $z_{t}^{1}$, yet since $\operatorname{Var}\left(z_{t}^{1}\right)<\operatorname{Var}\left(z_{t}\right)$ (this follows from (18) and the assumption that the $e_{i t}^{*}$ follows a random walk) this is not necessarily the case on a proportional basis.

Idiosyncratic shocks

From (17) and (15), and the fact that, due to the Law of Large Numbers, $E_{t}^{*, o} \simeq E_{t}^{*}$, we have that:

$$
v_{i t}^{o}= \begin{cases}v_{i t}+\Delta \epsilon_{i t}^{e}+\theta \Delta \epsilon_{i t}^{h} & \text { for Model 1, } \\ v_{i t}+(1-\theta) \Delta w_{i t} & \text { for Model } 2 .\end{cases}
$$

Thus the observed cross-section of idiosyncratic shocks will be a convolution of the true cross-section and measurement error.

It follows that:

$$
\operatorname{Var}\left(v_{t}^{\circ}\right)= \begin{cases}\operatorname{Var}\left(v_{t}\right)+2 V & \text { for Model 1, } \\ \operatorname{Var}\left(v_{t}\right)+2(1-\theta)^{2} \sigma_{w}^{2} & \text { for Model 2 }\end{cases}
$$

where $V=\operatorname{Var}\left(\epsilon_{i t}^{e}+\theta \epsilon_{i t}^{h}\right)$. We conclude that observed idiosyncratic shocks will bave a larger variance than the true shocks.

Based on (29) and some algebra we may express the observed first-order serial correlation of idiosyncratic shocks, $\rho_{v}^{0}$ in terms of the actual first-order serial correlation, $\rho_{v}$ :

$$
\rho_{v}^{o}= \begin{cases}\frac{\operatorname{Var}\left(v_{t}\right) \rho_{i}-V}{\operatorname{Var}\left(v_{t}\right)+2 V} & \text { for Model 1, } \\ \frac{\operatorname{Var}\left(v_{t}\right) \rho_{i}-(1-\theta)^{2} \sigma_{2}^{2}}{\operatorname{Var}\left(v_{t}\right)+2(1-\theta)^{2} \sigma_{t}^{2}} & \text { for Model } 2 .\end{cases}
$$

It follows that, if idiosyncratic shocks are serially uncorrelated, measured idiosyncratic shocks are negatively serially correlated.

A similar calculation for the correlation between idiosyncratic shocks and pre-shock deviations leads to:

$$
\rho\left(v, z^{1}\right)^{0}= \begin{cases}\frac{\sigma\left(v_{t}\right) \sigma\left(x_{t}^{1}\right) \rho\left(v, x^{1}\right)+\theta^{2} \sigma_{t, h}^{2}}{\left(\operatorname{Var}\left(v_{t}\right)+2 V\right)^{1 / 2}\left(\operatorname{Var}\left(z_{t}^{1}\right)+\theta^{3} \sigma_{\varepsilon, h}^{2}\right)^{1 / 2}} & \text { for Model 1, } \\ \frac{\sigma\left(v_{t}\right) \sigma\left(z_{t}^{1}\right) \rho\left(v, z^{1}\right)+\theta(\theta-1) \sigma_{t}^{2}}{\left(\operatorname{Var}\left(v_{t}\right)+2(\theta-1)^{2} \sigma_{t}^{2}\right)^{1 / 2}\left(\operatorname{Var}\left(z_{t}^{1}\right)+\theta^{2} \sigma_{t}^{2}\right)^{1 / 2}} & \text { for Model 2. }\end{cases}
$$

We conclude that if there is no correlation between idiosyncratic shocks and pre-shock de- 
viations, the data with measurement error will show positive correlation. ${ }^{55}$ The expressions above also show that the size of the observed positive correlation is smaller for large values of the variance of idiosyncratic shocks.

Effective hazand

The effective hazard evaluated at $z^{\circ}$ is estimated by averaging (over $i$, for all firms with deviation $\left.z^{\circ}\right)$ the $\left(\Delta e_{i t}^{\circ} / z^{\circ}\right)^{\prime}$. This is equivalent to averaging the following expression:

$$
\frac{z^{\circ}+\xi_{i t}}{z^{\circ}} \frac{\Delta e_{i t}\left(z_{i t}\right)}{z_{i t}}+\frac{y_{i t}}{z^{\circ}}
$$

where

$$
\xi_{i t}= \begin{cases}\theta \epsilon_{i t}^{h}+\Delta \epsilon_{i t}^{e} & \text { for Model 1, } \\ (1-\theta) w_{i t}-w_{i, t-1} & \text { for Model 2 }\end{cases}
$$

and

$$
y_{i t}= \begin{cases}\Delta \epsilon_{i t}^{e} & \text { for Model 1, } \\ \Delta w_{i t} & \text { for Model } 2 .\end{cases}
$$

If in (33) we condition on $\xi=x$, average over the values of $\Delta e$ and then average with respect to $\xi$ we obtain:

$$
A^{\circ}(z)=\frac{1}{z} \mathrm{E}\left[\left(z+\xi_{t}\right) A\left(z+\xi_{t}\right)\right]
$$

Using a Taylor expansion then leads to the main expression of this subsection:

$$
A^{\circ}(z) \simeq A(z)+\sigma_{\zeta}^{2}\left[\frac{A^{\prime}(z)}{z}+\frac{A^{\prime \prime}(z)}{2}\right],
$$

where $\sigma_{\xi}^{2}$ denotes the variance of $\xi_{i t}$, so that:

$$
\sigma_{\xi}^{2}= \begin{cases}\theta^{2} \sigma_{c, h}^{2}+2 \sigma_{c, e}^{2} & \text { for Model 1, } \\ \left(1+(\theta-1)^{2}\right) \sigma_{w}^{2} & \text { for Model } 2\end{cases}
$$

Equation (37) has many implications. First we have that if the actual effective hazard is constant (as in a partial adjustment model), then the estimated hazard is an unbiased estimate of the true hazard.

Next we focus our attention on the case of an increasing hazard (i.e. for $A(z)$ increasing with respect to the absolute value of $z$ ). We also assume that it is sufficiently smooth

\footnotetext{
${ }^{55}$ In the case of model 2 this requires that $\theta>1$ which holds for most series.
} 
(continuous first derivative). It follows that $A^{\prime}(z) / z$ is positive for all $z$; thus the estimated hazard is biased upwards for values of $z$ where the true effective hazard is locally convex. This will be the case for small values of $z$, since a smooth, increasing hazard necessarily is convex near $z=0$. Since $A(z)$ is usually bounded from above (by one) we shall have that for large values of $z$ the bias tends to disappear. Of course, the variance of the estimates will be larger than it would have been in the absence of measurement error.

\section{Distribution of conditional jumps}

It follows from (33) that the distribution of adjustments, conditional on an observed deviation of $z$ and on adjusting by a fraction of $\left(\Delta e_{i t}^{o} / z_{i t}\right)=-\alpha$, is normal with mean $-\alpha$ and variance $c / z^{2}$, where $c$ is a positive constant that depends on $\alpha, \theta$ and the variance of measurement error. It follows, based on combining the latter with an argument similar to that of the preceding subsection, that (i) the estimated distribution of conditional jumps is a scale mixture of normal distributions, where the scaling kernel is not centered around the true $z$ but exhibits a bias similar to that derived earlier. This bias may be large for small $|z|$ and becomes negligible as $|z|$ becomes large; (ii) the additional variance introduced by measurement error decreases with the magnitude of $z$; (iii) if the conditional densities have a spike at $j=0$ (no adjustment) then the estimated conditional density will have local maxima at $j=0$. The maxima will be less spread out for large (absolute) values of $z$; (iv) if the conditional densities have spikes at $j=-1$ (full adjustment) then the estimated density will have a local maximum for $j \simeq-1$. This maxima will be more notorious and closer to $j=-1$ for larger (absolute) values of $z$. 


\section{References}

Abraham, Katherine, and Lawrence Katz, 1986, "Cyclical Unemployment: Sectoral Shifts or Aggregate Disturbances?" Journal of Political Economy, 94, 507-522.

Bar-Man, Avner, and Alan S. Blinder, 1992, "Consumer Durables: Evidence on the Optmality of Doing Nothing," Journal of Money, Credit and Banking 24, May, 253-272.

Beaulieu, Joseph, 1991, "Aggregate Movements in Durable Goods with Fixed Costs of Adjustment," mimeo.

Bertola, Giuseppe and Ricardo J. Caballero, 1990, "Kinked Adjustment Costs and Aggregate Dynamics," NBER Macroeconomics Annual, $V$, 237-287.

Bils, Mark, 1987, "The Cyclical Behavior of Marginal Cost and Price," American Economic Review, 77, no. 5, (December), 838-855.

Blanchard, Olivier and Peter Diamond, 1989, "The Beveridge Curve," Brookings Papers on Economic Activity 1989:1, 1-60.

Blanchard, Olivier and Peter Diamond, 1990, "The Cyclical Behavior of Gross Flows of Workers in the United States," Brookings Papers on Economic Activity 1990:2, 85-155.

Blinder, Alan, 1981, "Retail Inventory Behavior and Business Fluctuations," Brookings Papers on Economic Activity 1981:2, 443-505.

Bresnahan, Timothy and Valerie Ramey, 1994, "Output Fluctuations at the Plant Level," Quarterly Journal of Economics, 109, no. 3 (August), 593-624.

Caballero, Ricardo, 1992, "A Fallacy of Composition," American Economic Review, 82, no. 5 (December), 1279-1292.

Caballero, Ricardo, 1993, "Durable Goods: An Explanation for their Slow Adjustment," Journal of Political Economy, 101, 351-384.

Caballero, Ricardo and Eduardo Engel, 1991 "Dynamic $(S, s)$ Economies," Econometrica 59 , November, $1659-86$.

Caballero, Ricardo and Eduardo Engel, 1992 "Beyond the Partial Adjustment Model," American Economic Review, papers and proceedings, 82, (May), 360-364.

Caballero, Ricardo and Eduardo Engel, 1993 "Microeconomic Adjustment Hazards and Aggregate Dynamics," Quarterly Journal of Economics, 108, no.2 (May), 313-358.

Caballero, Ricardo and Mohamad Hammour, 1994a, "The Cleansing Effect of Recessions," American Economic Review, 84,, no. 5, 1350-1368.

Caballero, Ricardo and Mohamad Hammour, 1994b "On the Timing, Pace, and Efficiency of Creative Destruction," MIT mimeo. 
Caplin, Andrew, 1985, "Variability of Aggregate Demand with (S,s) Inventory Policies," Econometrica, 59,, 1395-1409.

Caplin, Andrew and Daniel Spulber, 1987, "Menu Costs and the Neutrality of Money," Quarterly Journal of Economics, 102, 703-725.

Caplin, Andrew and John Leahy, 1991, "State-Dependent Pricing and the Dynamics of Money and Output," Quarterly Journal of Economics, 106, 638-708.

Davis, Steven J. and John Haltiwanger, 1990, "Gross Job Creation and Destruction: Microeconomic Evidence and Macroeconomic Implications," NBER Macroeconomics Annual, $V, 123-168$.

Davis, Steven J. and John Haltiwanger, 1992, "Gross Job Creation, Gross Job Destruction, and Employment Reallocation," Quarterly Journal of Economics, 107, no. 3 (August) 819-863.

Davis, Steven J. and John Haltiwanger, 1994, "Driving Forces and Employment Fluctuations: New Evidence and Alternative Interpretations," mimeo.

Davis, Steven J., John Haltiwanger, and Scott Schuh, 1994, Gross Job Flows, manuscript, U.S. Bureau of the Census.

Eberly, Janice, 1994, “Adjustment of Consumers' Durables Stocks: Evidence from Automobile Purchases," Journal of Political Economy, 102, no. 3 (June), 403-436.

Hall, Robert E., 1991, "Labor Demand, Labor Supply, and Employment Volatility," NBER Macroeconomics Annual, VI, 17-47.

Hamermesh, Daniel, 1989, “Labor Demand and the Structure of Adjustment Costs," American Economic Review, 79 674-689.

Hamermesh, Daniel, 1993, Labor Demand, Princeton University Press, Princeton NJ.

Lilien, David M., 1982, "Sectoral Shifts and Cyclical Unemployment," Journal of Political Economy 90, 777-193.

Mortensen, Dale T., 1992, "The Cyclical Behavior of Job and Worker Flows," working paper, Northwestern University.

Mortensen, Dale T. and Christopher Pissarides, 1992, "The Cyclical Behavior of Job Creation and Job Destruction," working paper, Northwestern University.

Sargent, Thomas J., 1978, "Estimation of Dynamic Labor Demand Schedules under Ratio nal Expectations," Journal of Political Economy, 86, $1009-1044$.

Shapiro, Matthew D., 1986, “The Dynamic Demand for Capital and Labor," Quarterly Journal of Economics, 101, 513-542. 
Figure 2.1

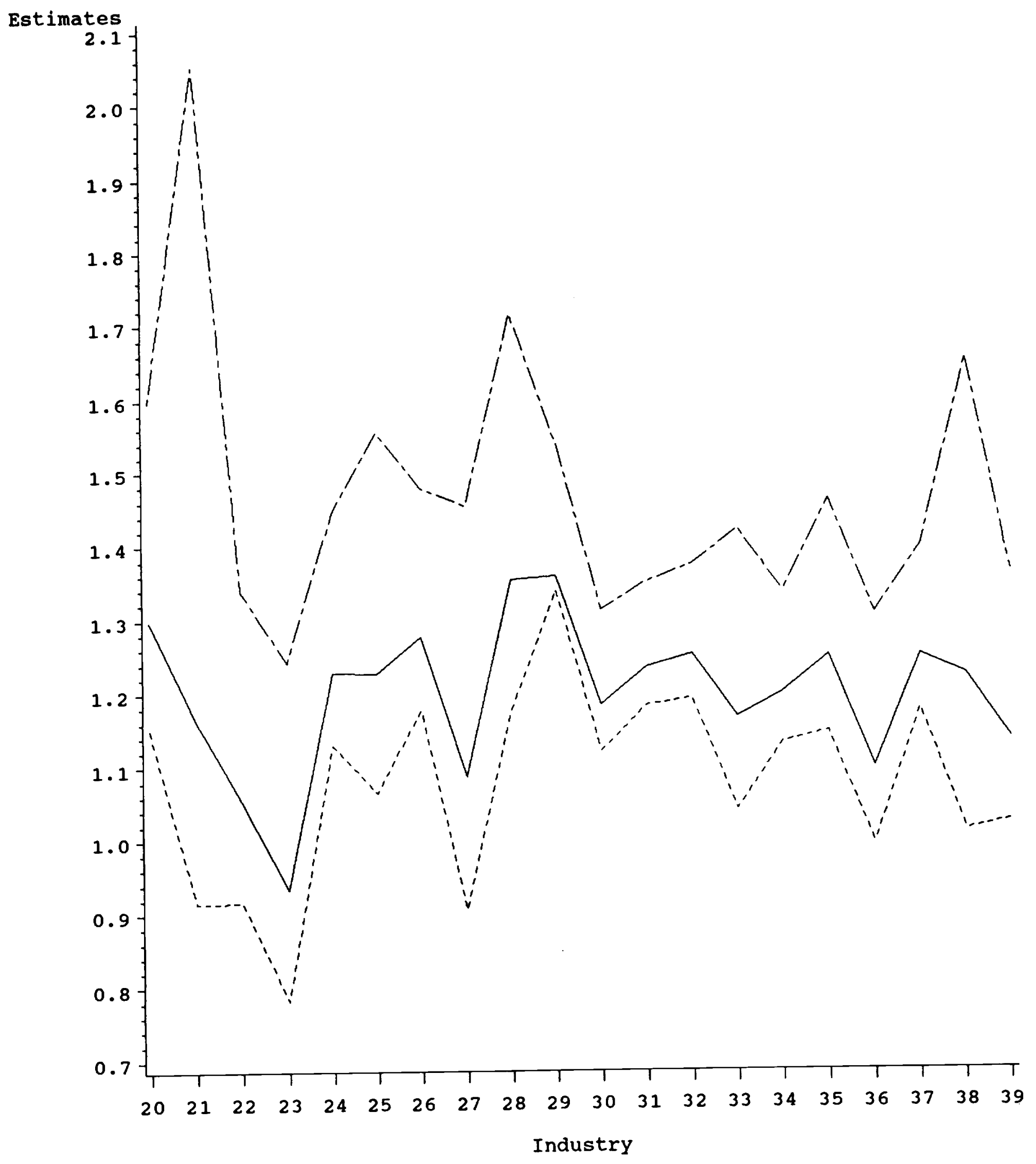


Figure 3.1

Average Effective Hazard

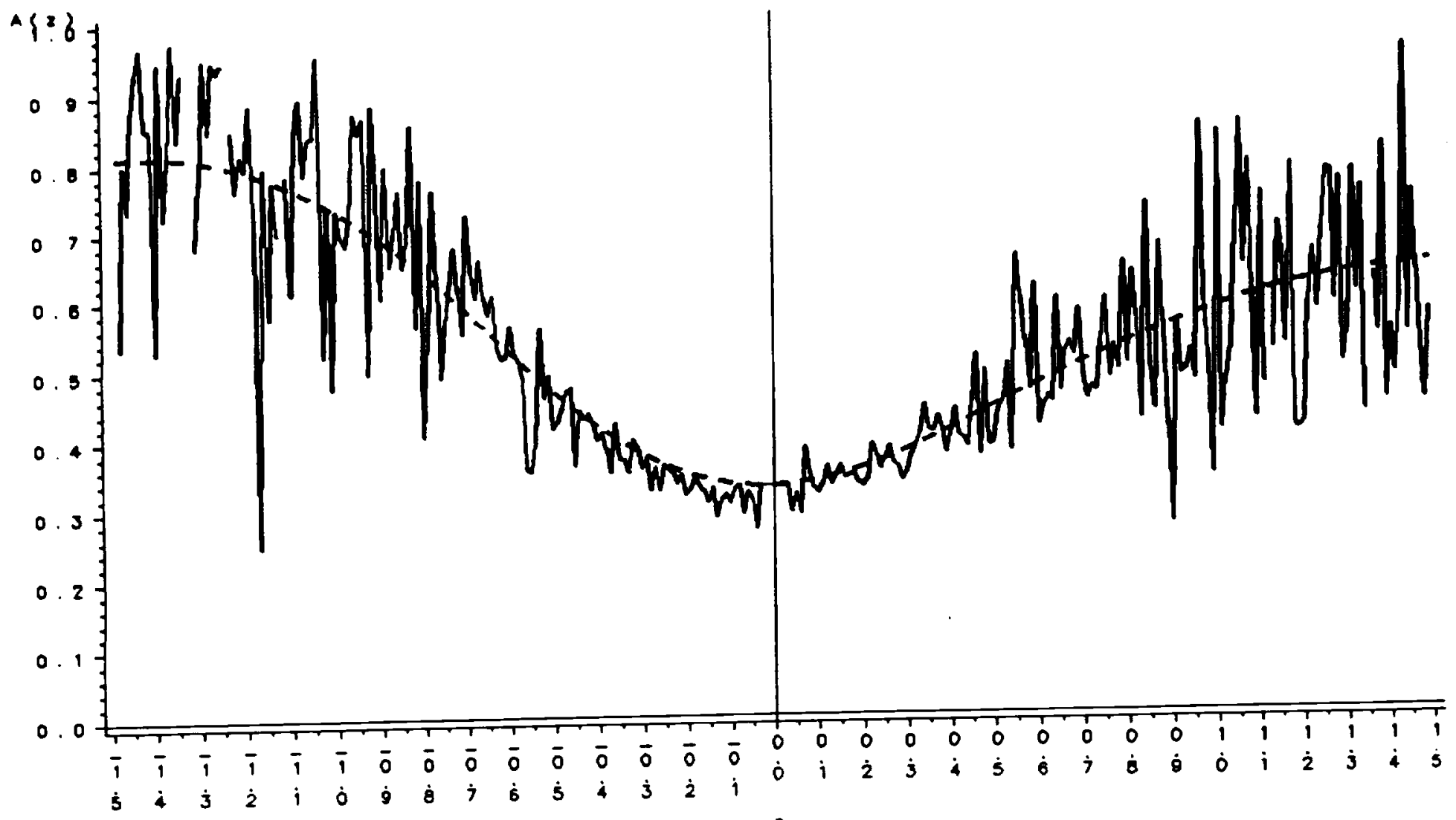

$$
\text { Average Distribution of }
$$

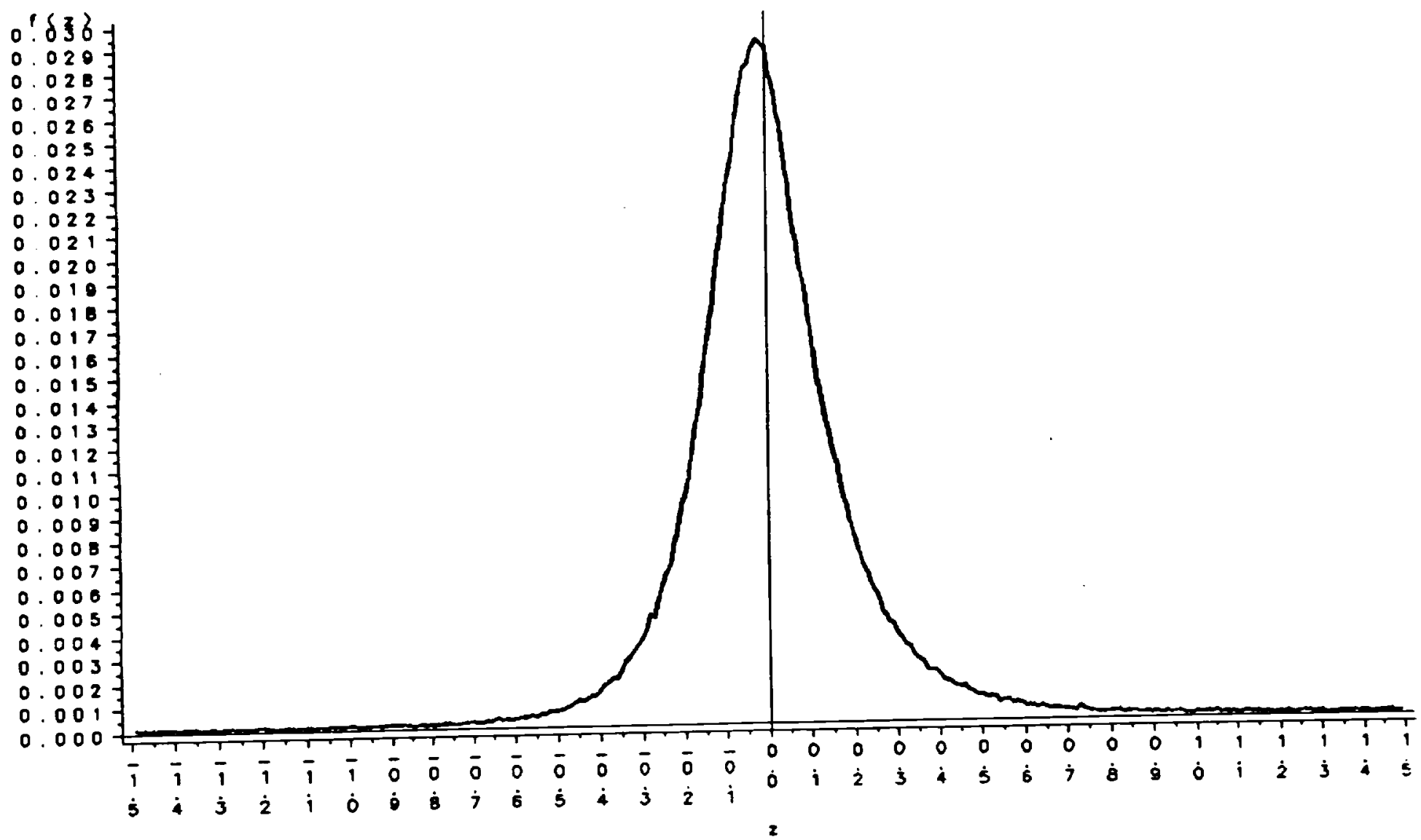

Figure 3.4 
Effective Hazard

olr.1
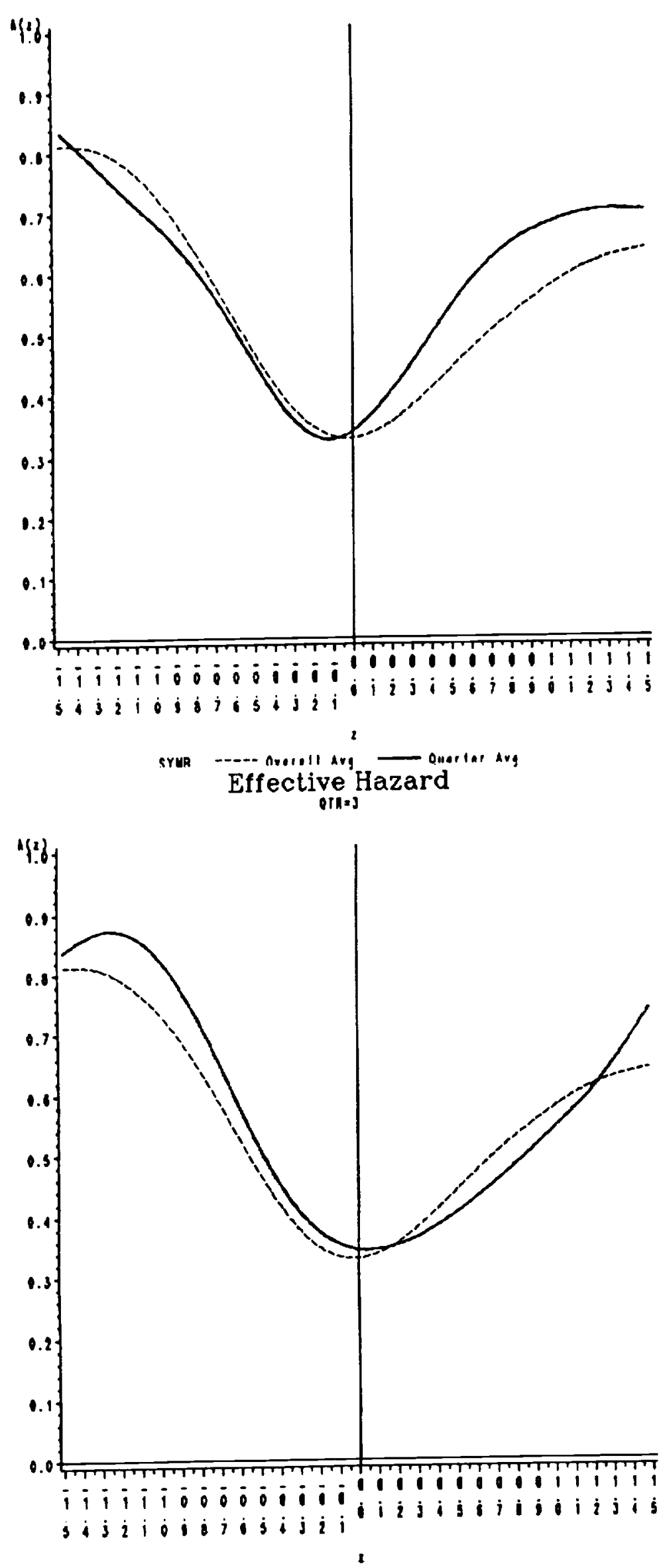

Effective Hazard

011.2

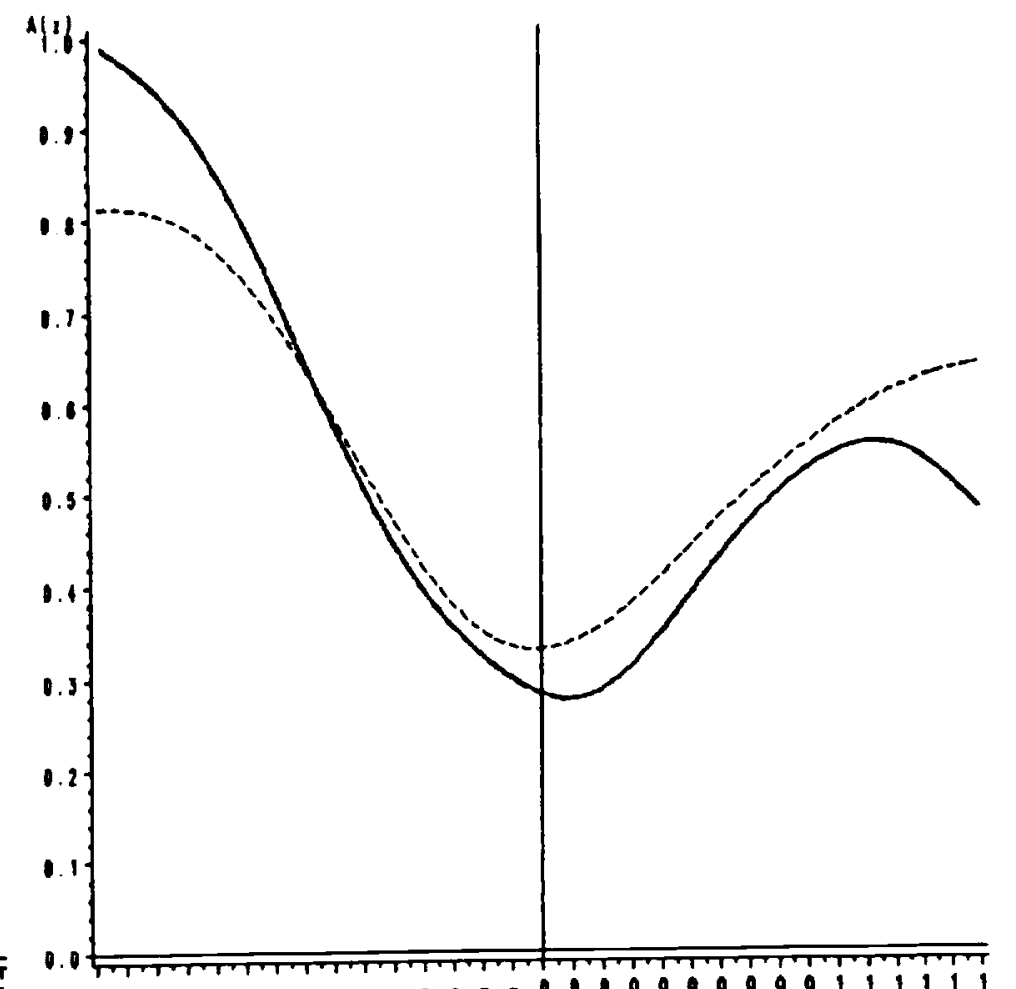

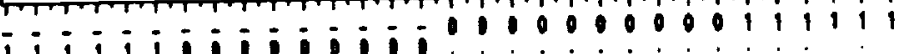
j i j $i$ i i jijijiji
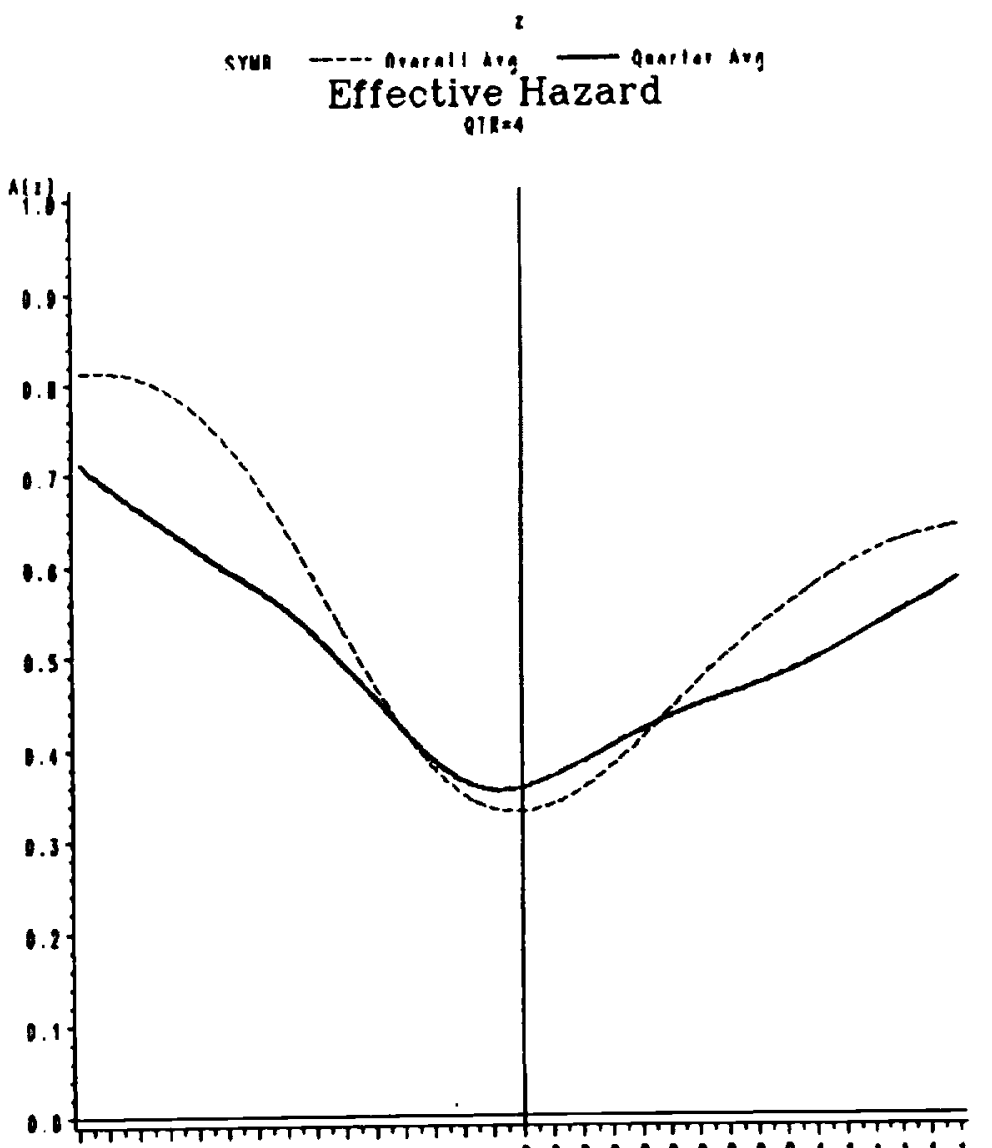

- i i i i a

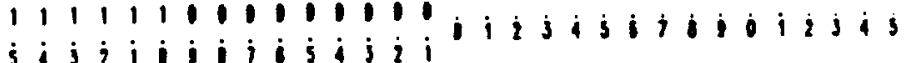

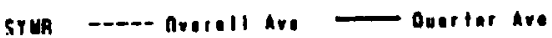


Effective Hazard

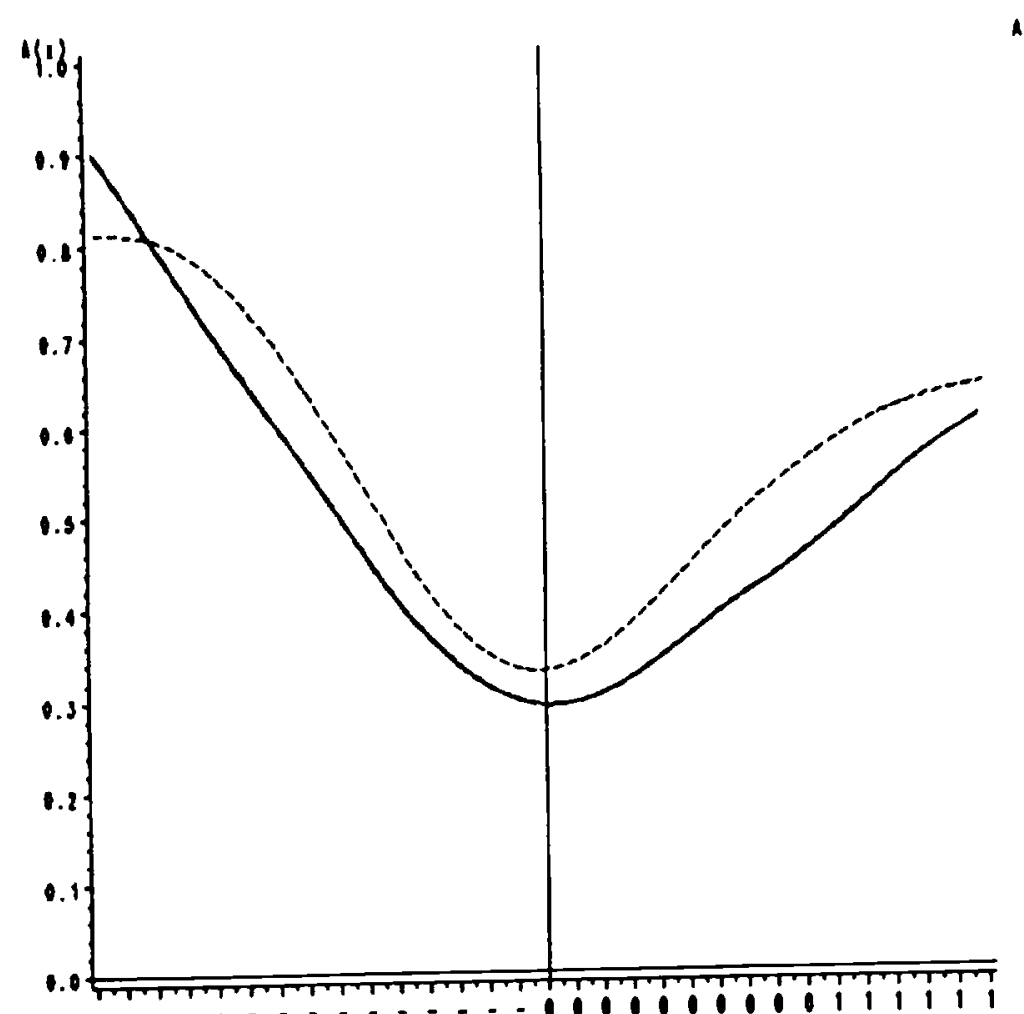

i i i i i

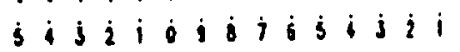

$$
\text { sYwa } \frac{\text { Ensuel ang }}{\text { Effective Hazard }}
$$

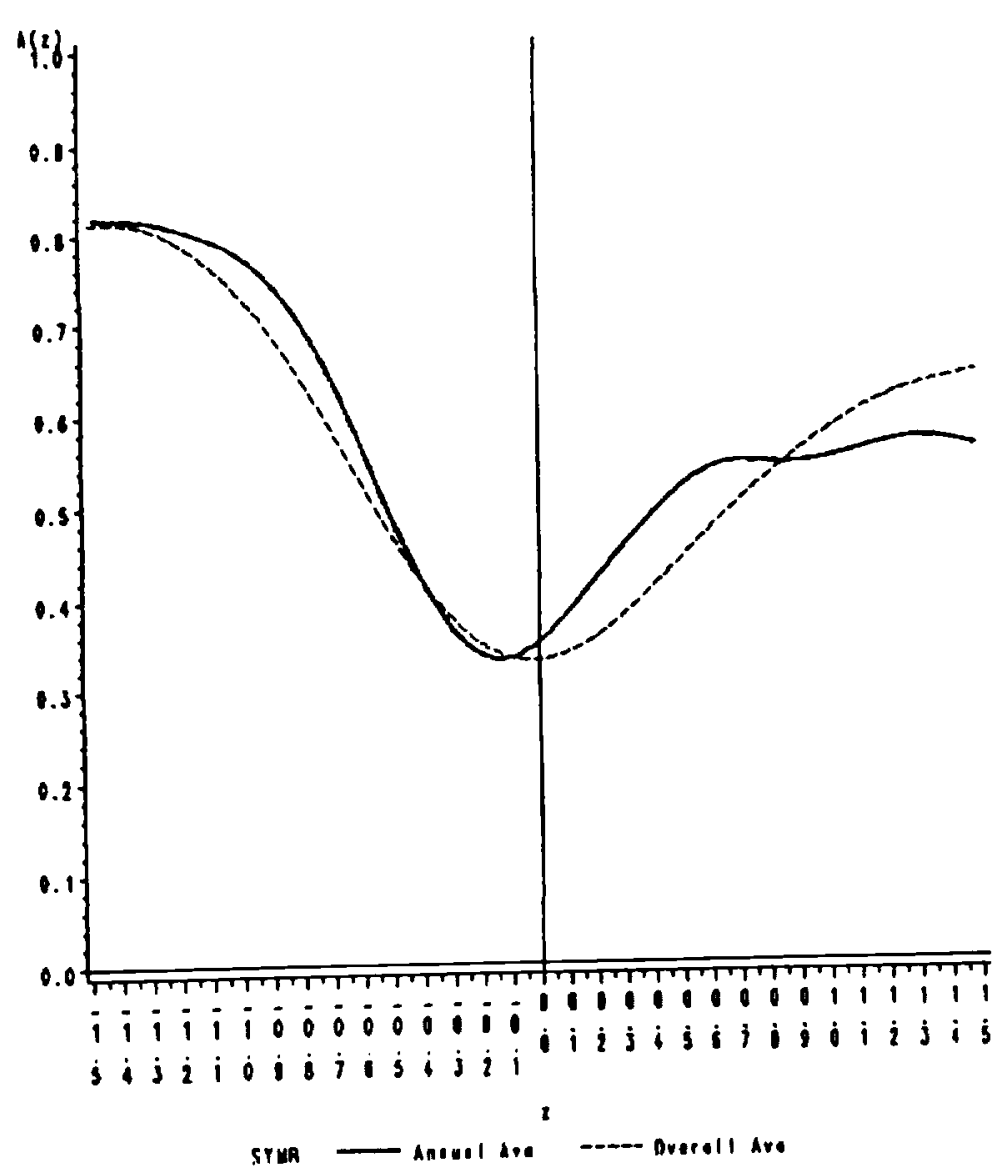

Effective Hazard

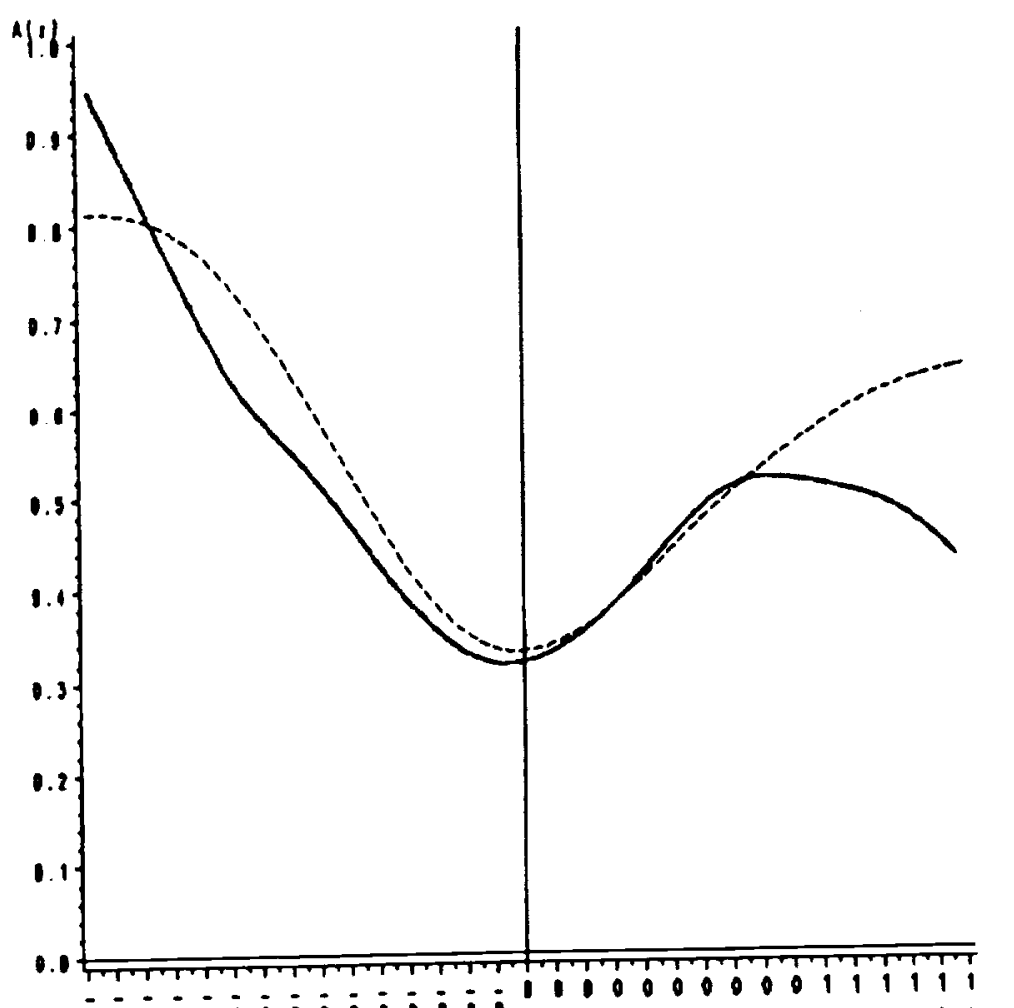

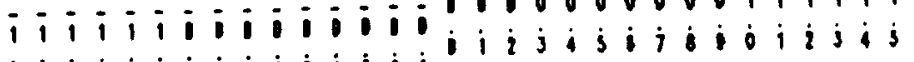

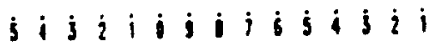

srun Eifective Hazard

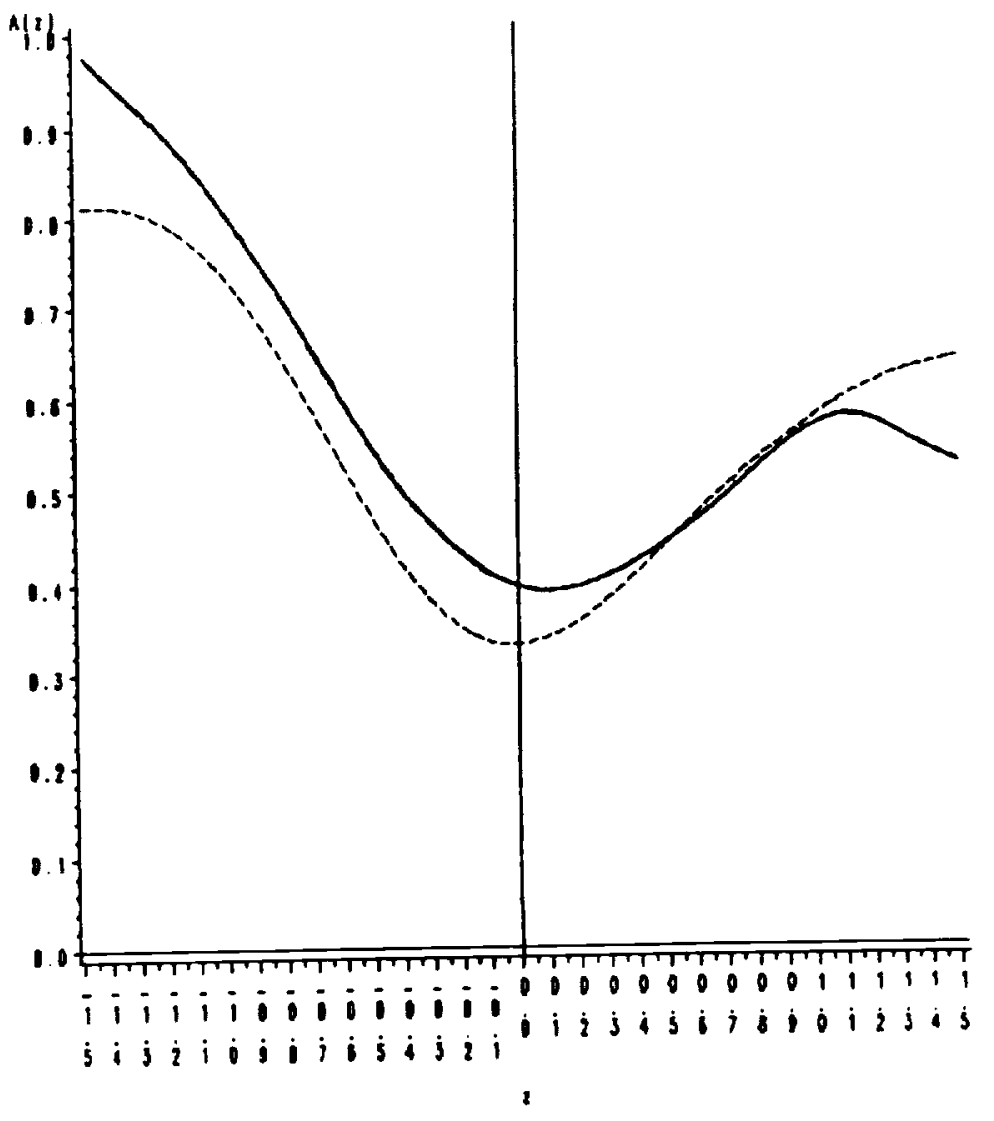

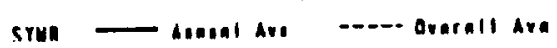


Effective Hazard rat."I

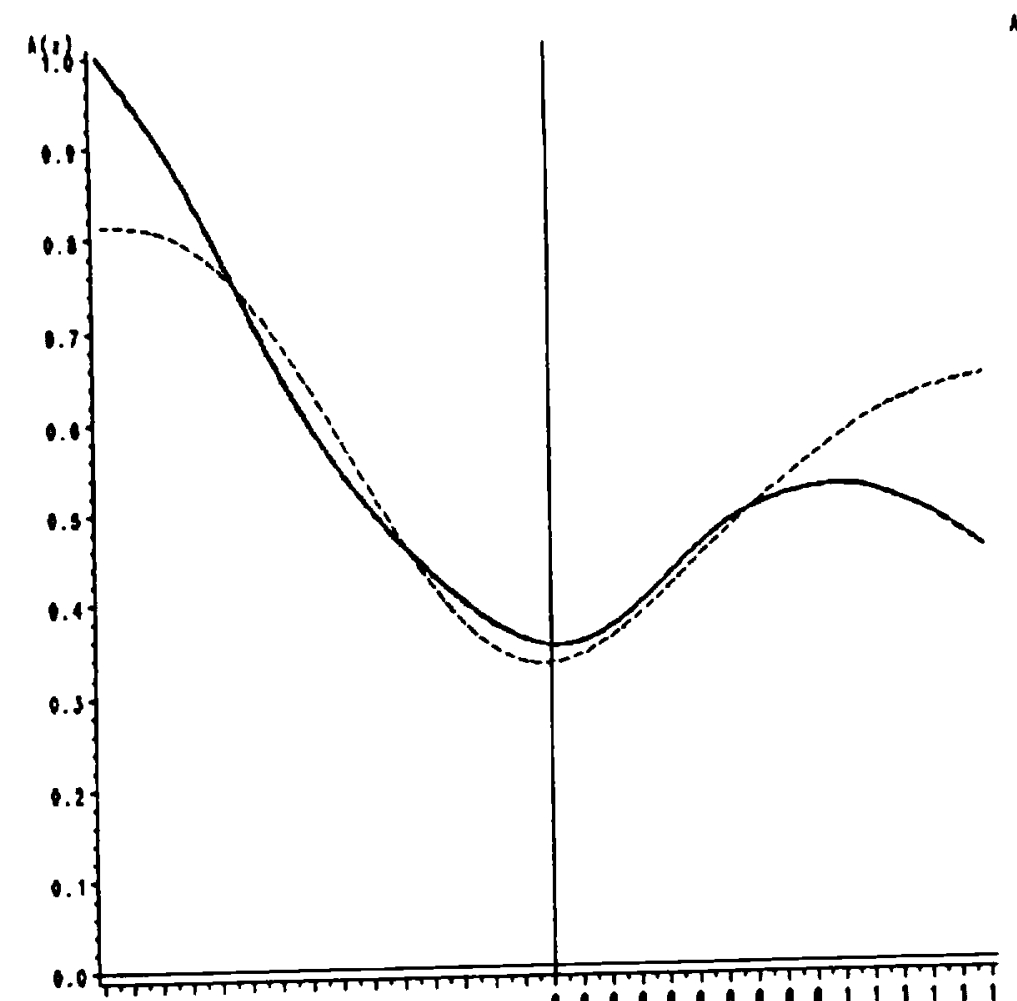

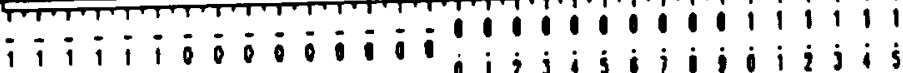

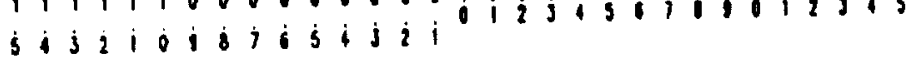

$$
\text { srua } \text { Effective Hazard }_{\text {reat=11 }}^{\text {nnous }}
$$

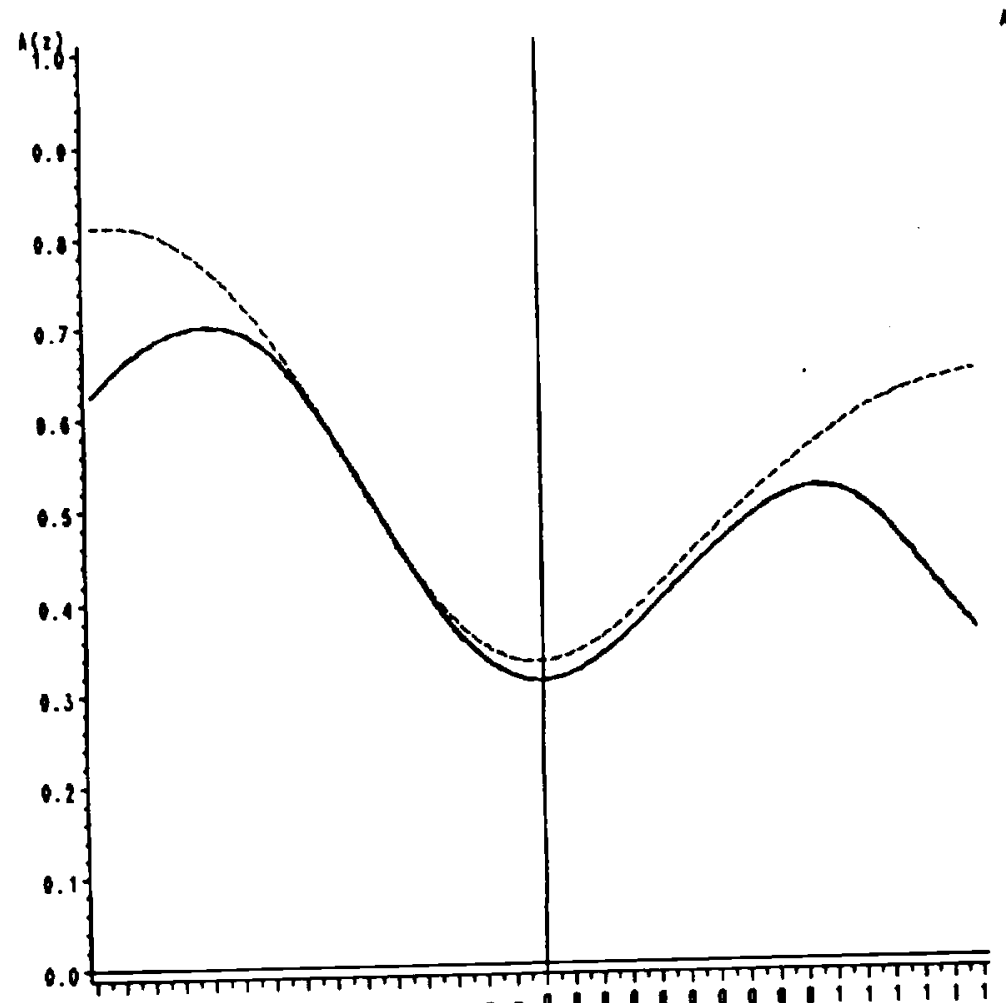

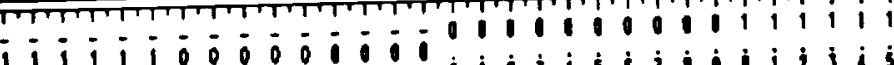

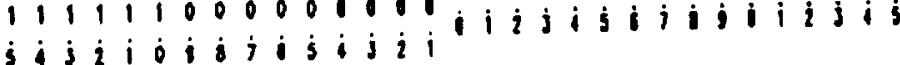

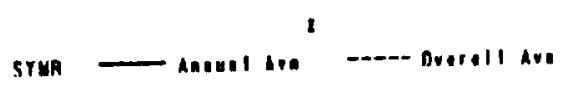

$\underset{\text { Effective Hazard }}{\text { EAfl }}$

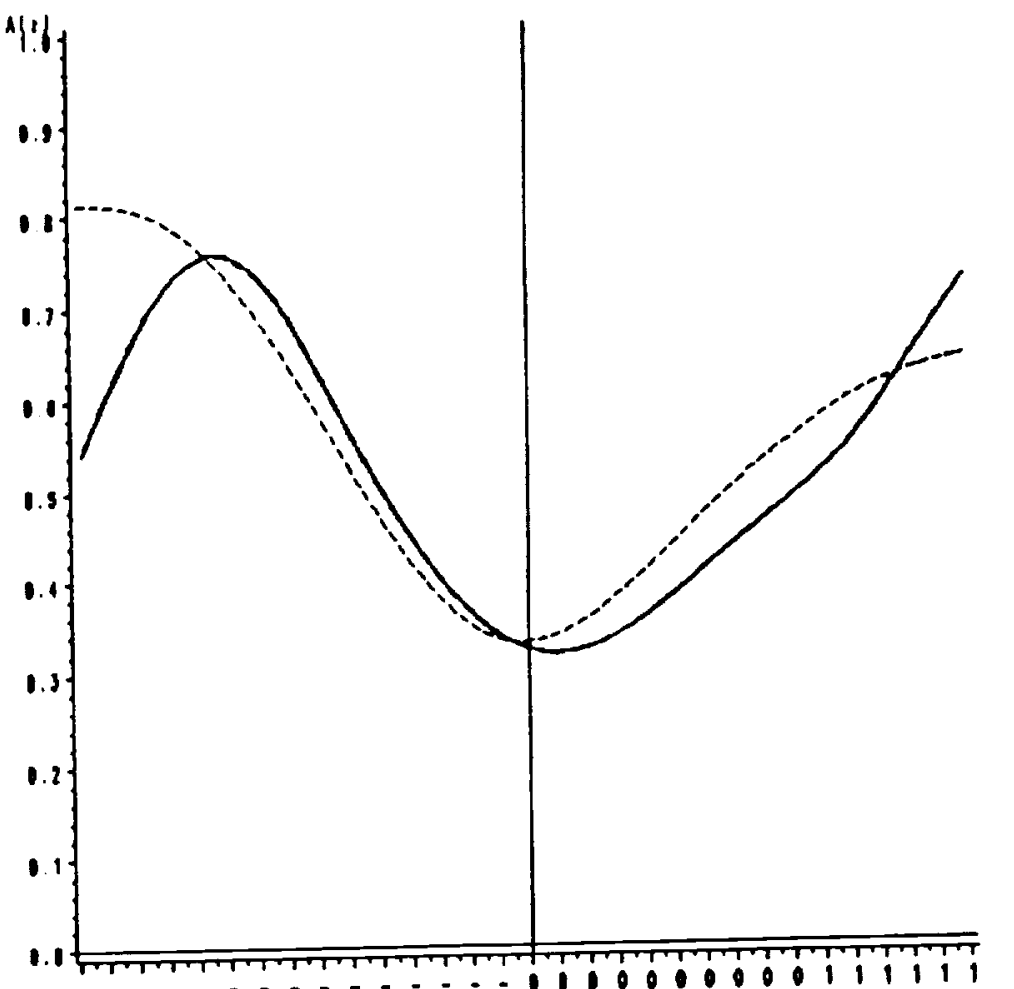

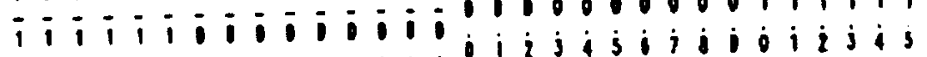
j i j i i j j i i j jiji
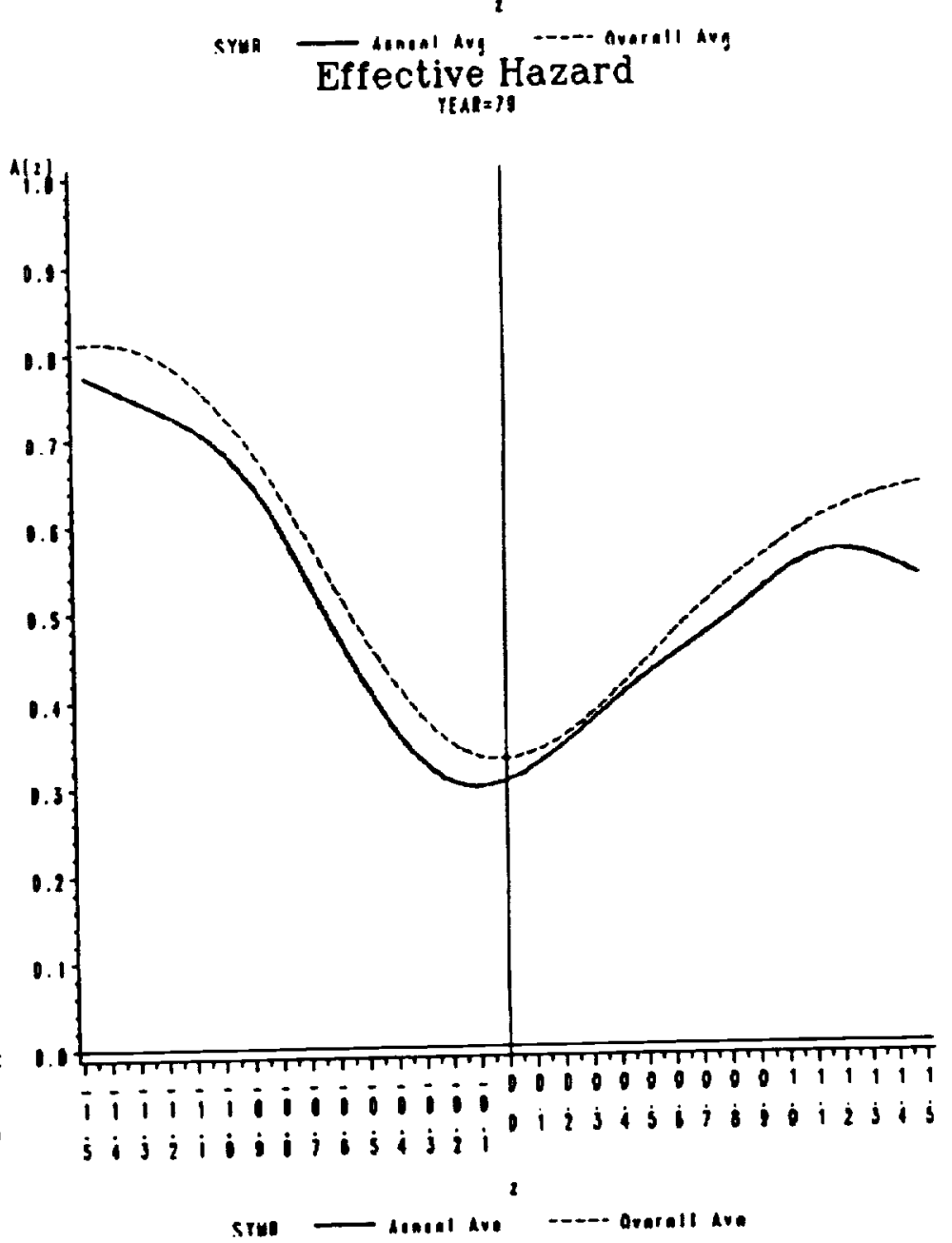
Mean (s.a.)

Figure 3.5
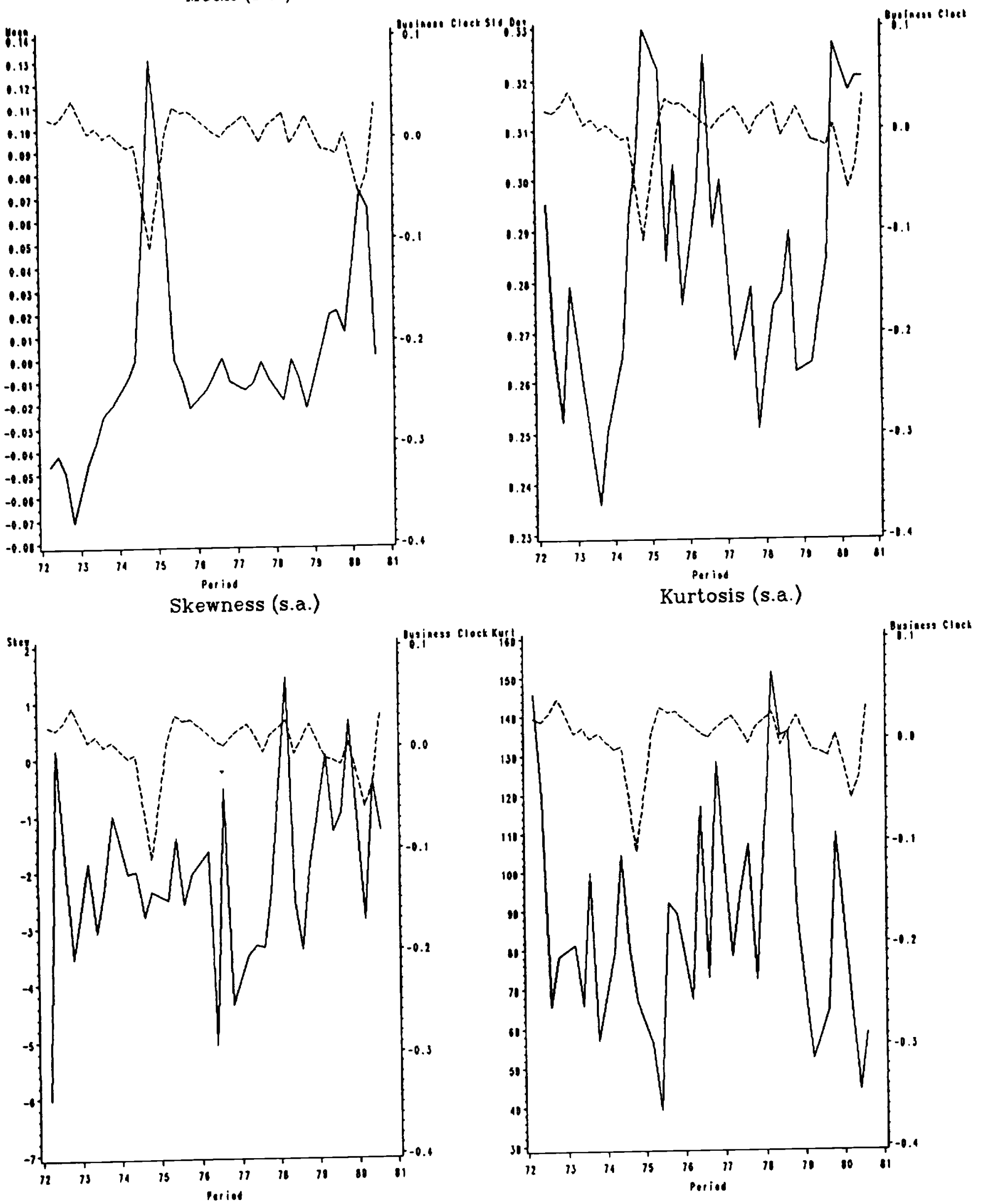
$\begin{array}{lll} & \text { Figure } 3.6 & \text { Skewness (s.a.) }\end{array}$
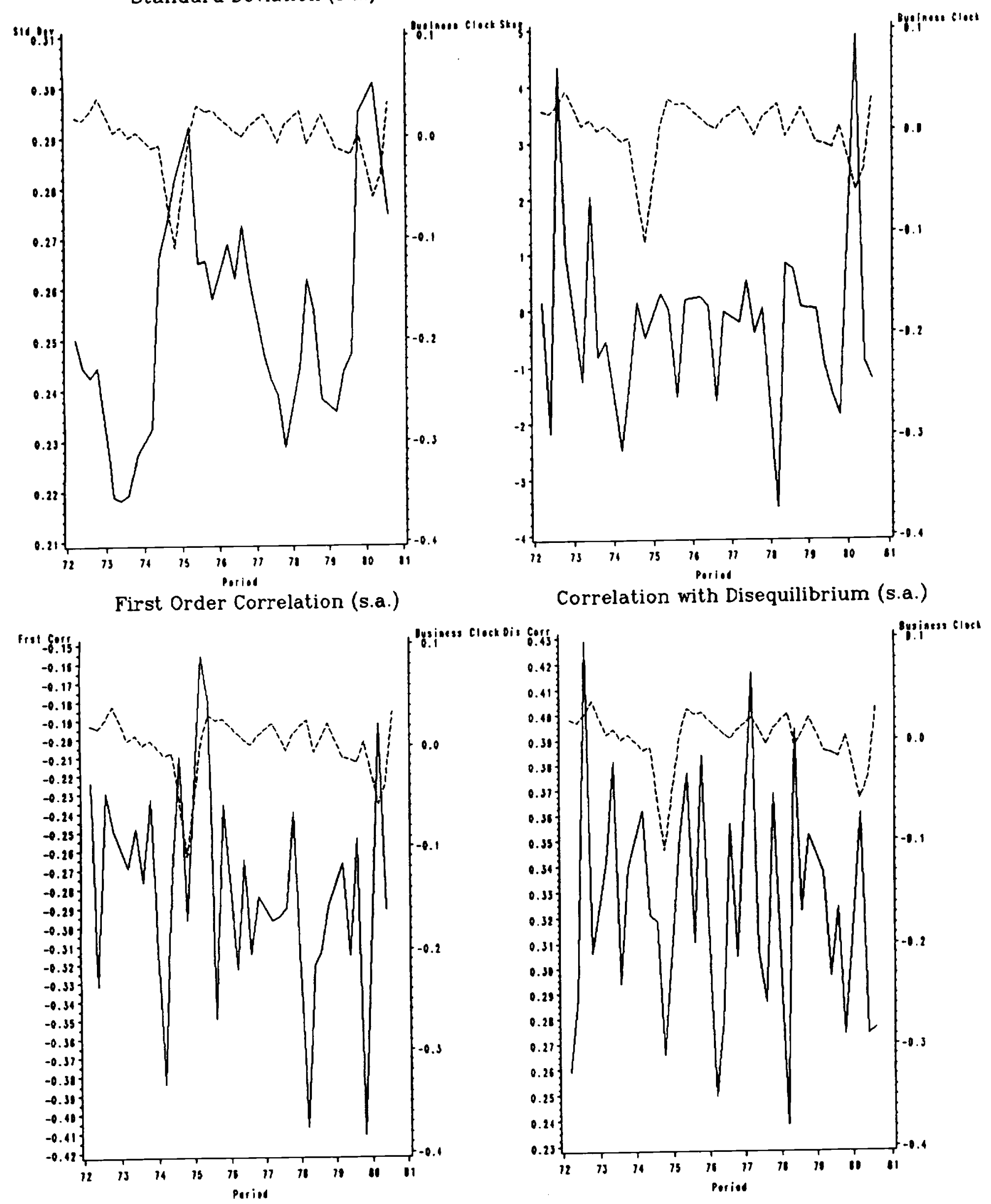


\section{Figure 3.7}

Average Normalized Conditional Jump, By GroupAverage Normalized Conditional Jump. By Group
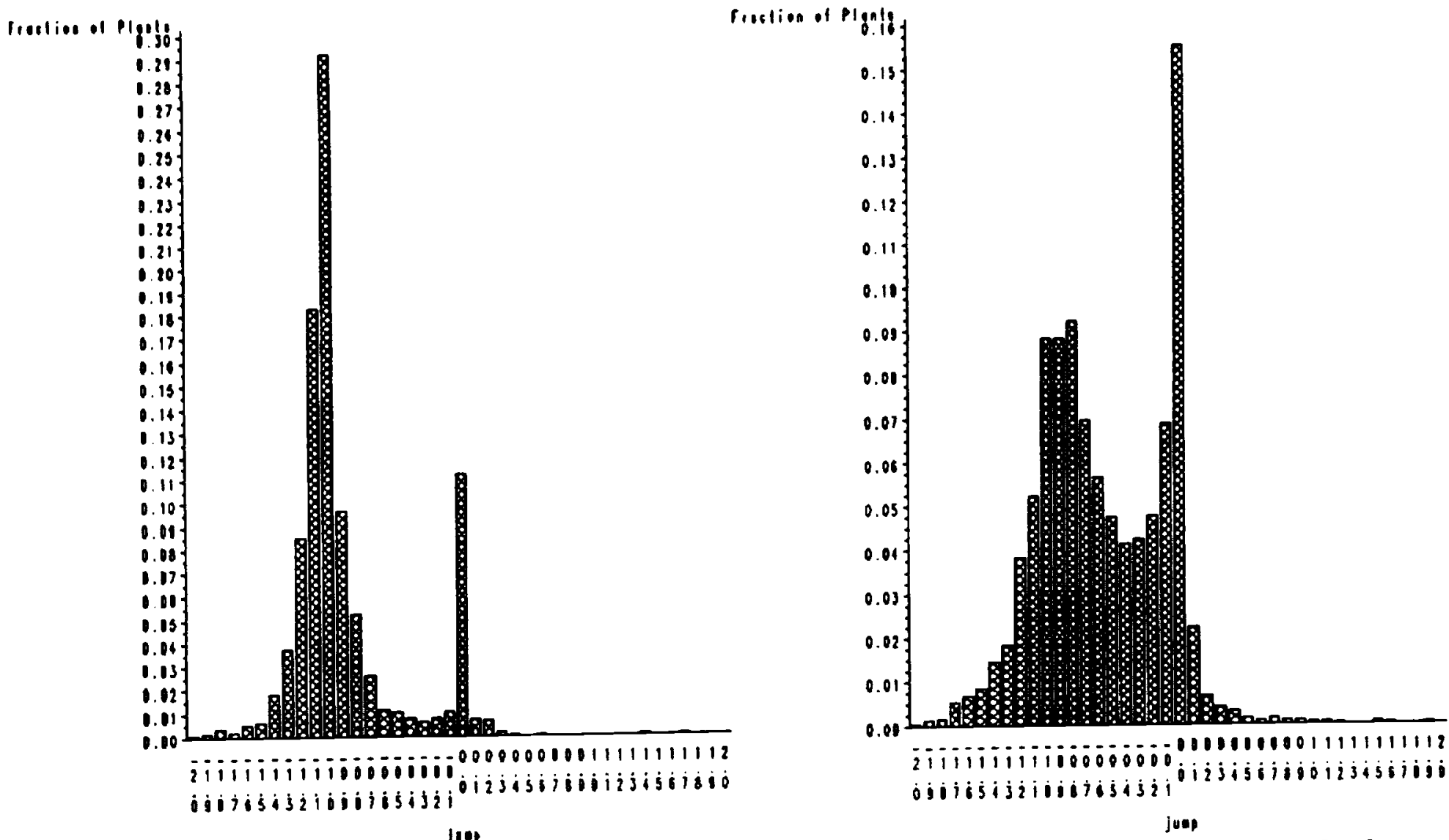

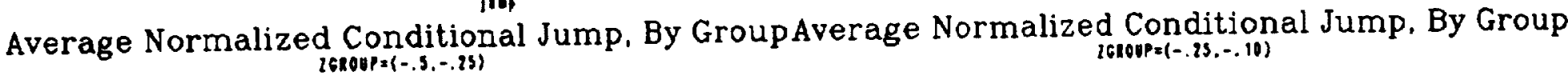
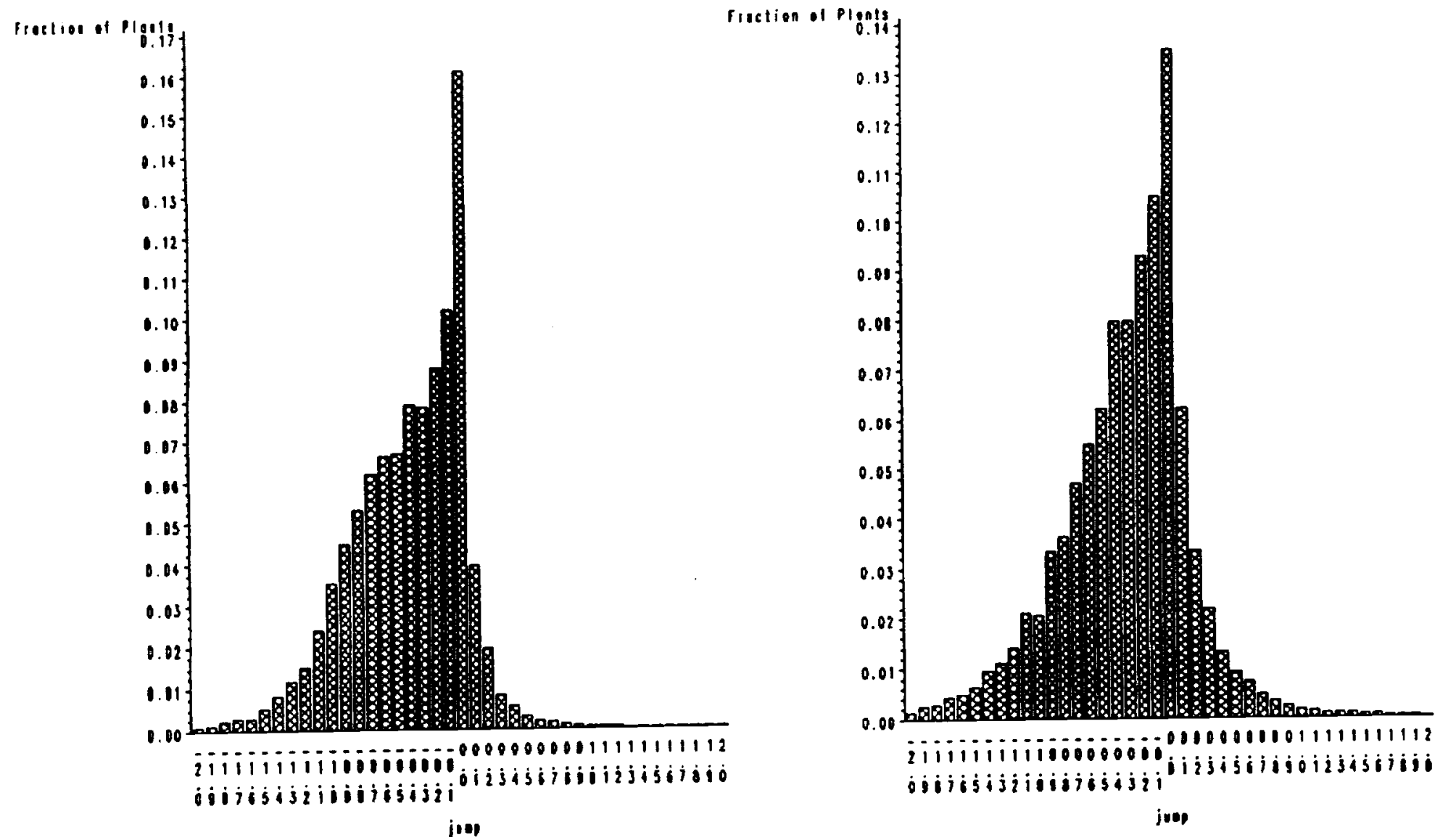


\section{Figure 3.7}

Average Normalized Conditional Jump, By GroupAverage Normalized Conditional Jump. By Group icroup $(.10, .25)$
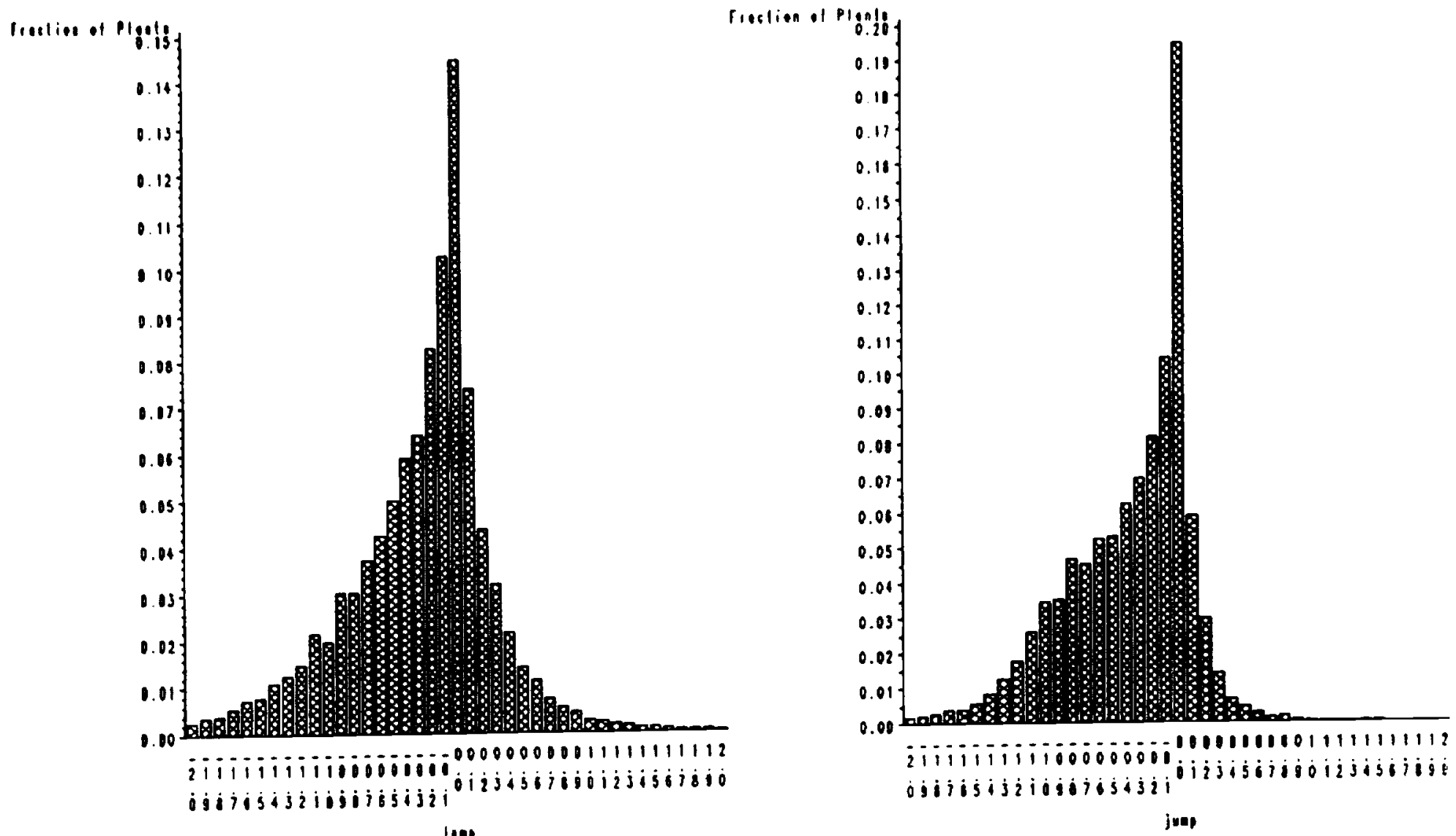

lou

Average Normalized Conditional Jump, By GroupAverage Normalized Conditional Jump. By Group zstouf $x$ (.5.1)
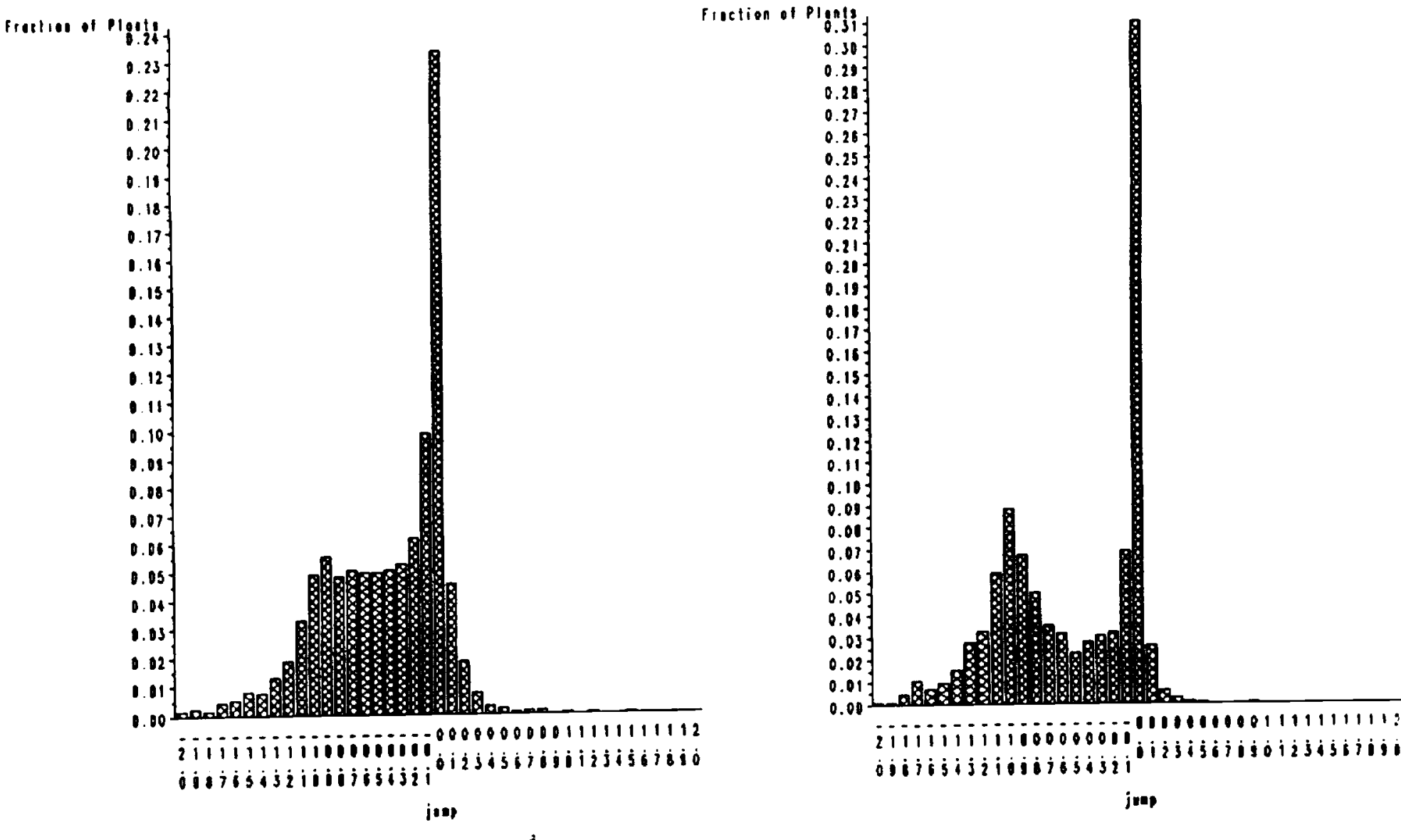
Figure 4.1 a
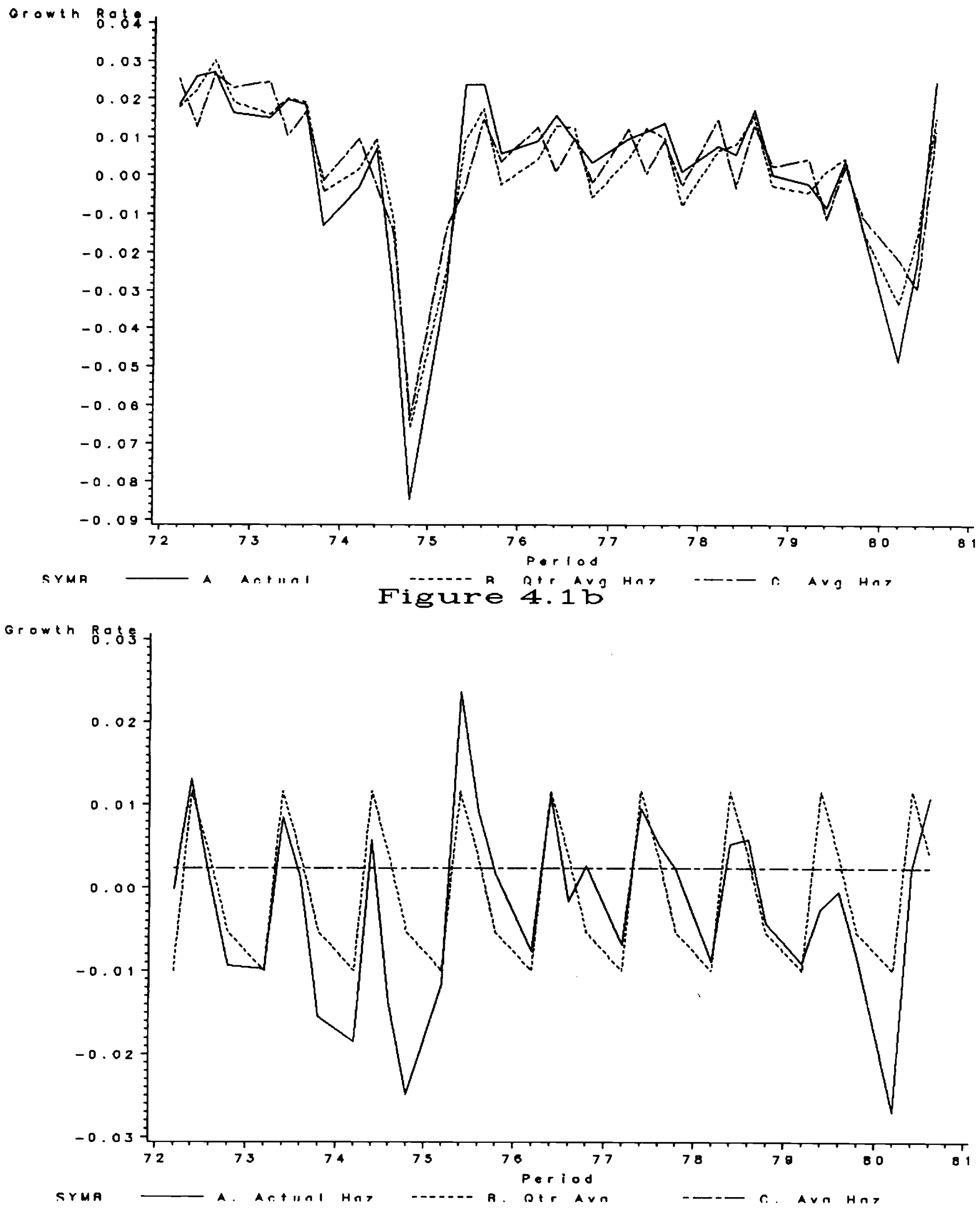
Figure 4.2

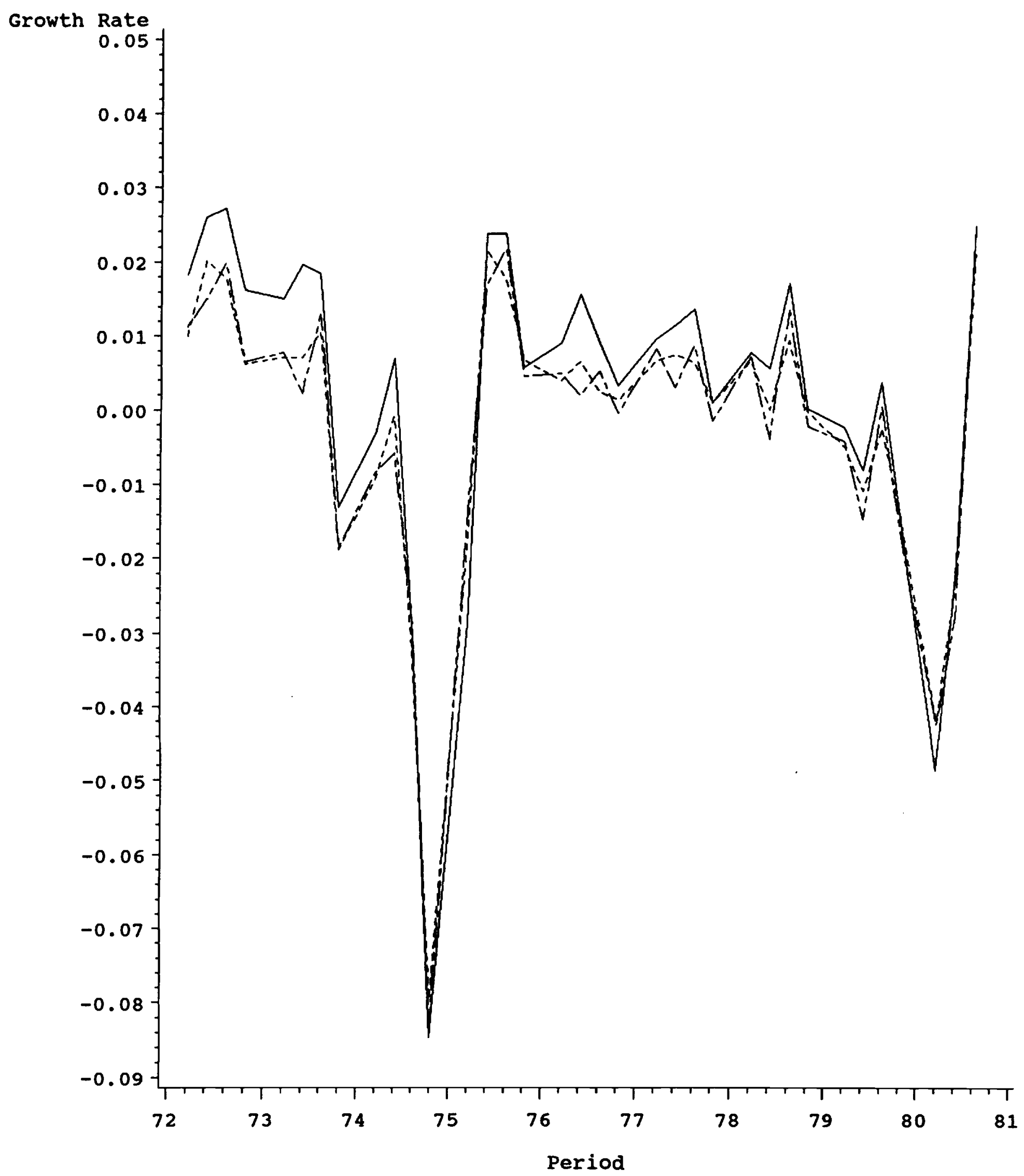


Figure 4.3

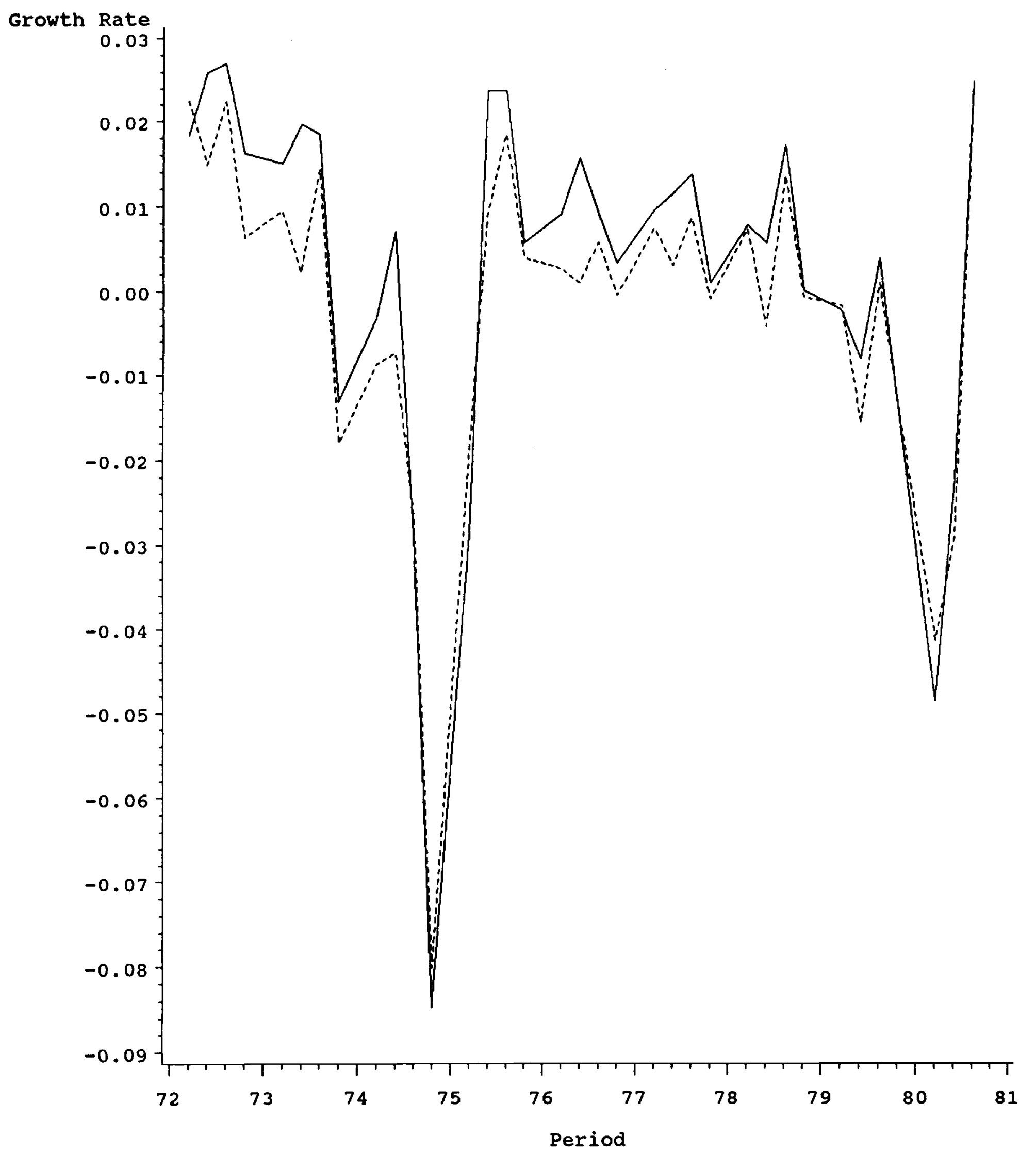




\section{Figure $5.1--$ Gross Flows}

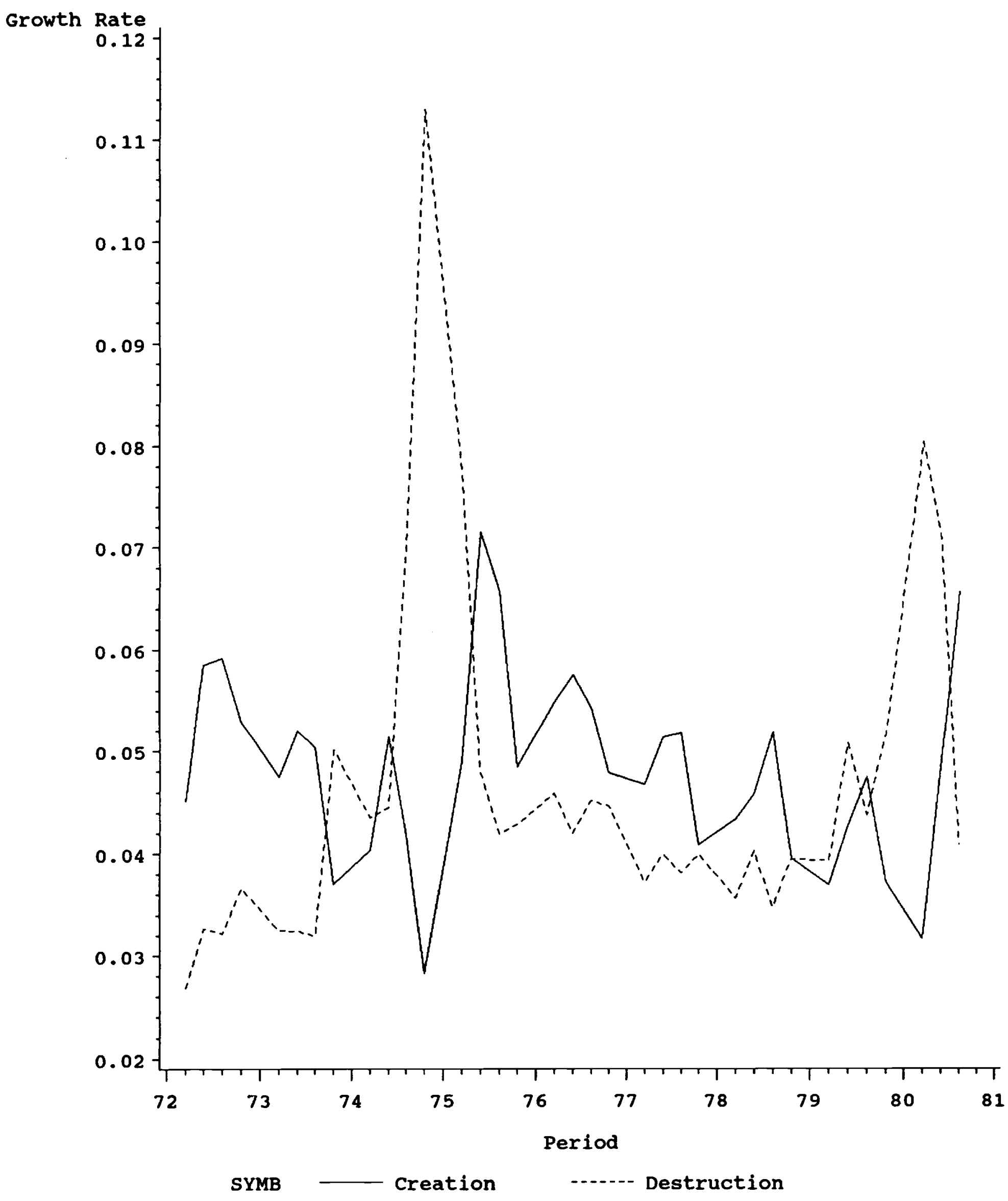

